The Impact of Learning Methods Used in Literacy on the Attitudes of Rural Women Towards Gender Equality Issue. (A Comparative Study between "Reflect Method" (Learning for Life) and The "Traditional Method" (Etalem Etnawar) in Manshaat Alkeram Village, Shebin Alqanater District, Kalyoubia Governorate, Egypt.

Jacinthe I. Rihan

Rural Sociology and Agriculture Extension Department, Faculty of Agriculture, Ain shams University, Arab Republic of Egypt.

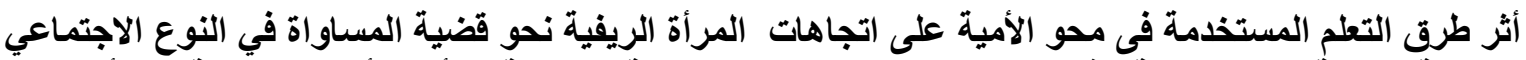

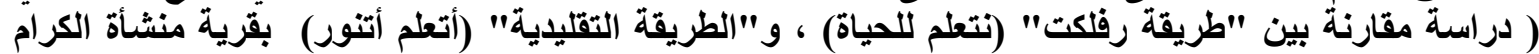

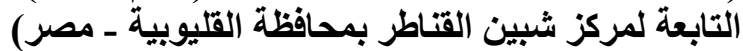

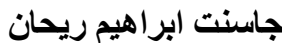

قنم المجتمع الريفى و الارشاد الزراعى،كلية الزراعة، جامعة عين شمس،جمهورية مصر العربية.

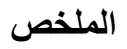

تعتبر الأمية في مصر, وخاصة في المناطق الريفية, وبين النساء, من المشاكل التي تعوق جهود التنمية والإصلاح, حيث بلغت نسبة الزبة الإناث

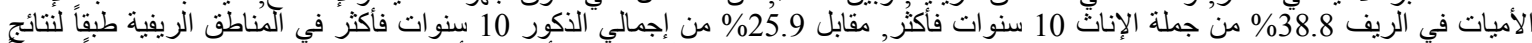

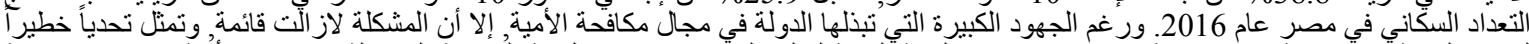

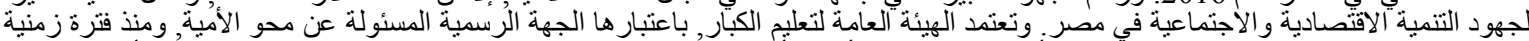

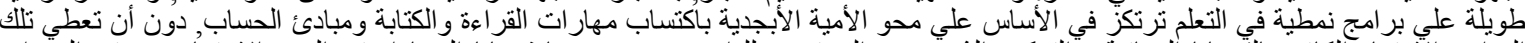

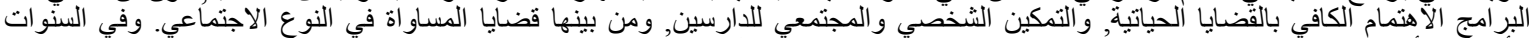

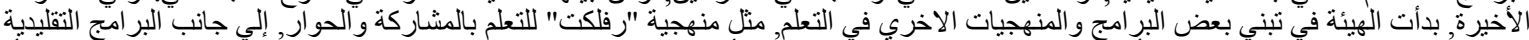

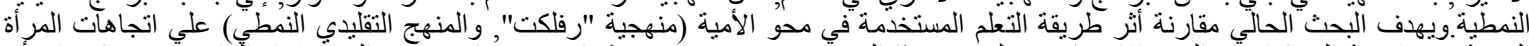

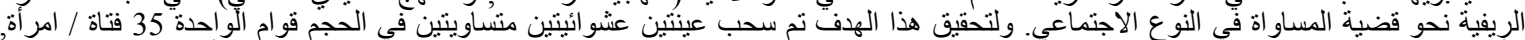

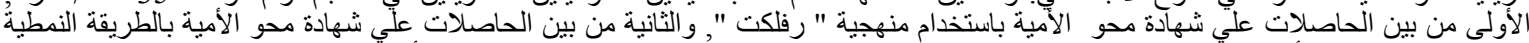

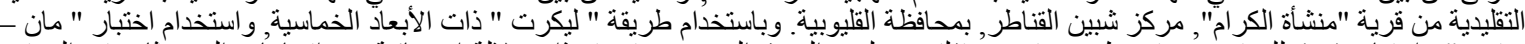

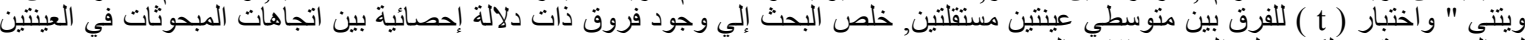

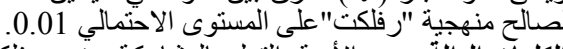

وفكرياً, وسد الفجوة النوعية في الدور الاجتماعي لتحويل الفتيات والمر أة التئ

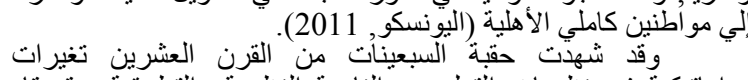

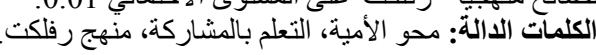

المقامة بالمانة

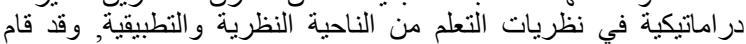

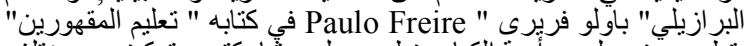

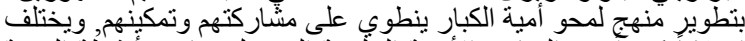

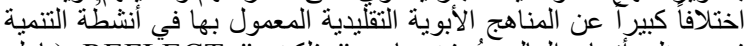

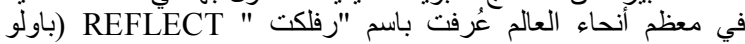
فريرى، 2002).

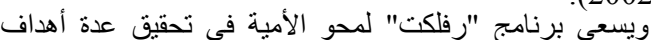

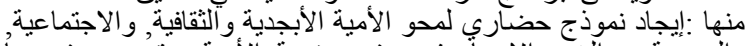

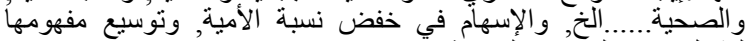

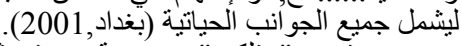

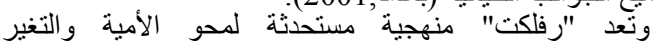

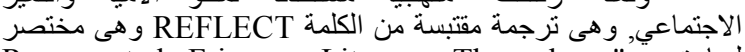

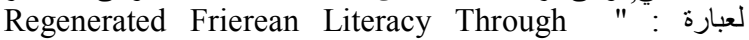
Empowering Community Techniques"

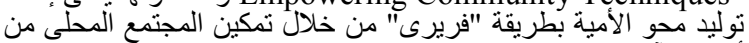

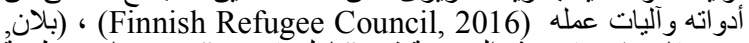

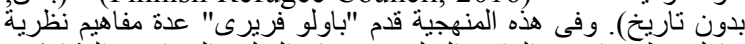

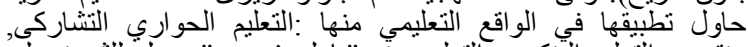

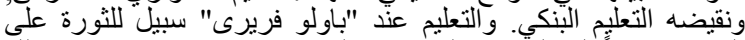

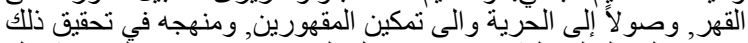

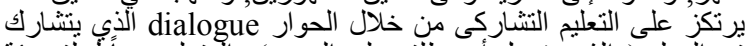

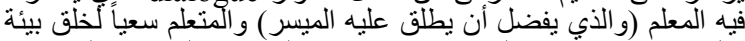

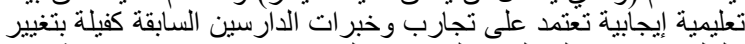

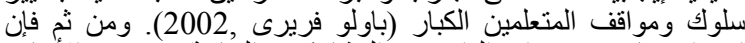

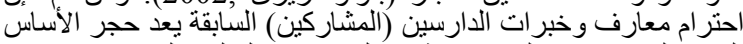

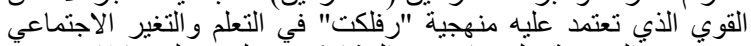

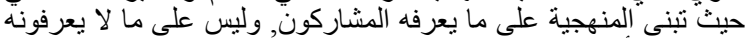

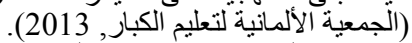

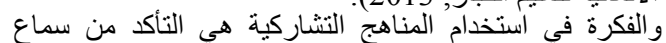

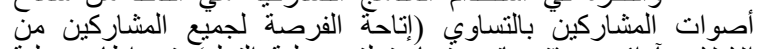

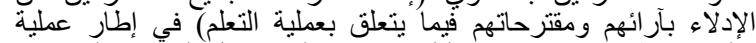

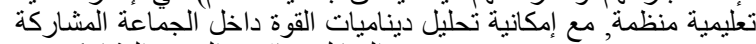

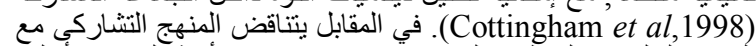

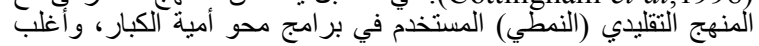

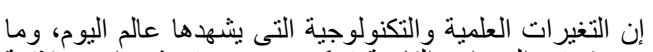

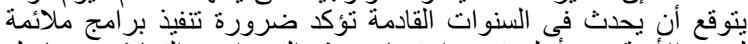

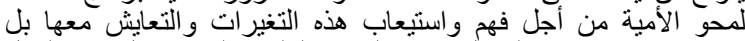

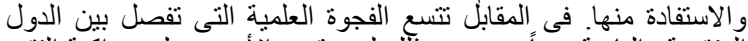

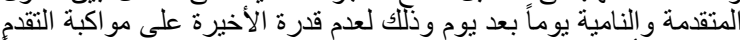

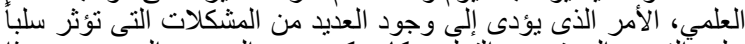

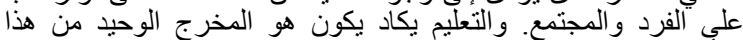

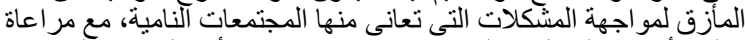

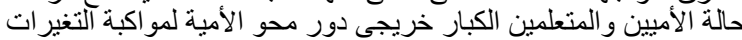
العلمية والتكنولوجية و التعايش معها.

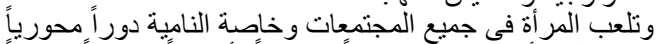

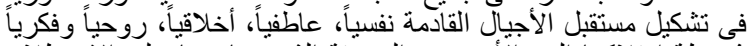

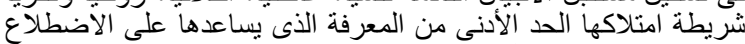

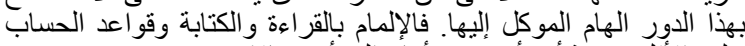

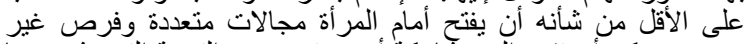

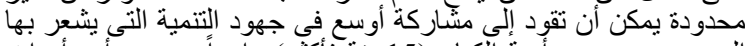

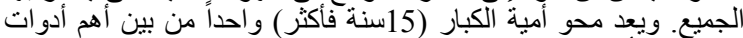

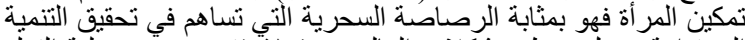

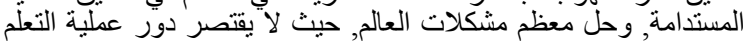
literacy

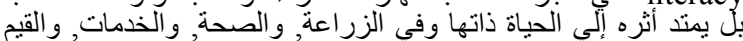

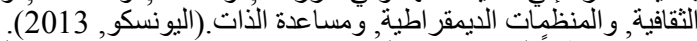

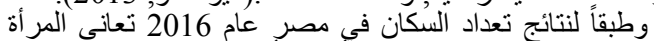

المصرية من ارتفاع كبير في معدل الآمية الأبجدية خاصة الإنة في المناطق

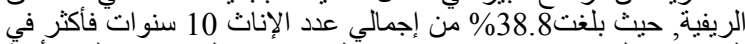

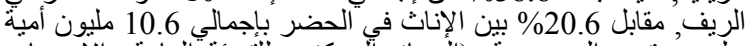

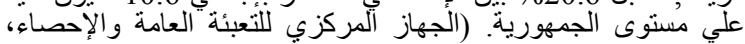

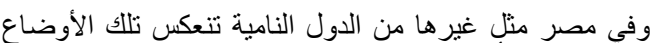

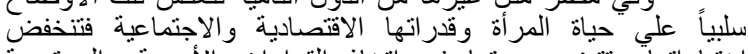

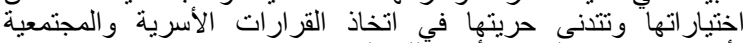

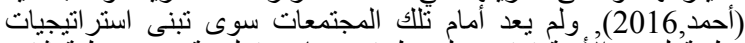

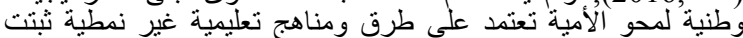

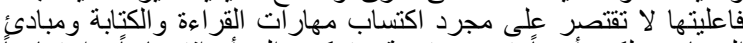

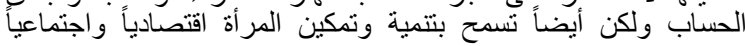




\section{Jacinthe I. Rihan}

منهجية "رفلكت" REFLECT للتعلم بالمشاركة:

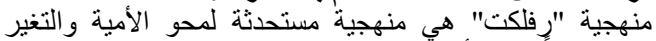

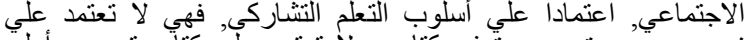

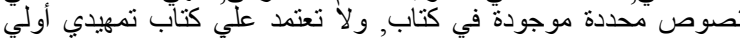

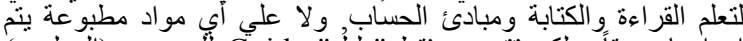

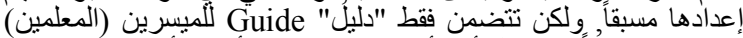

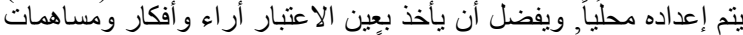

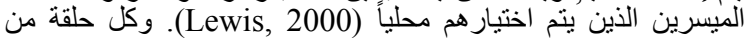
حلقات التعلم Literacy Circle (باولو فريري, 2002) والتيني يطلق التئ

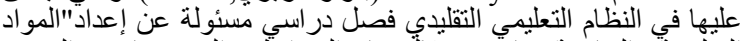

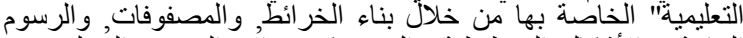

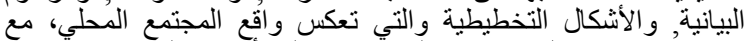

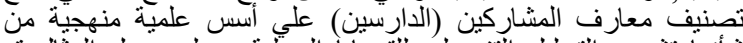

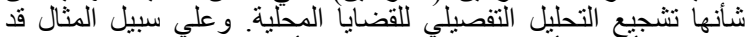

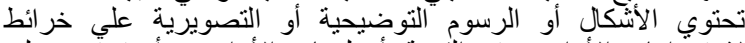

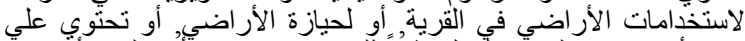

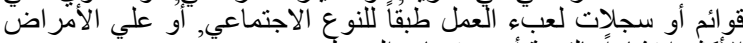
الأكثر انتشار أ بالقرية أو مستويات الدمل الدخول.

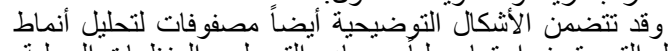

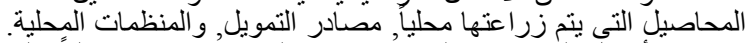

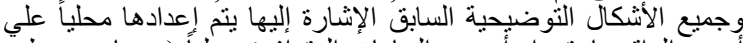

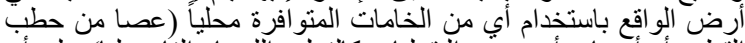

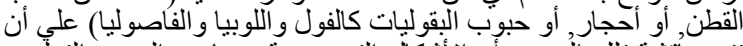

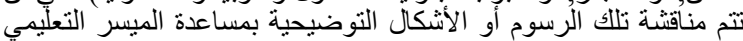

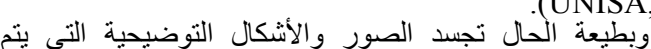
(UNISA, 2014)

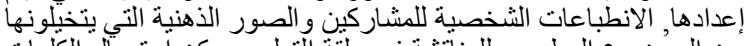

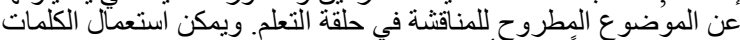

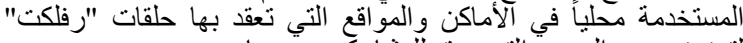

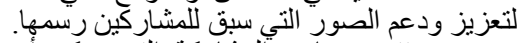

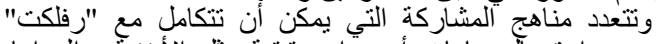

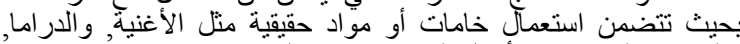

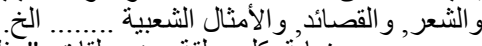

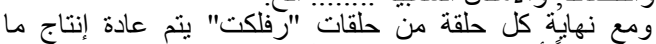

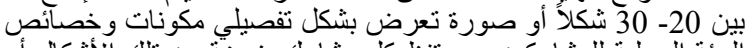

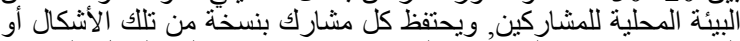

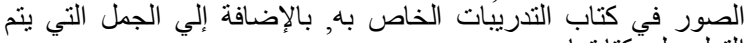

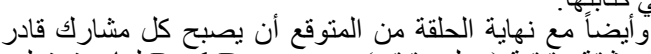
التعلم علي كتابتها.

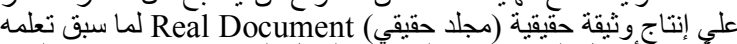

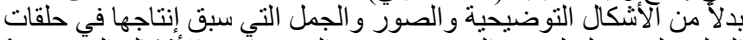

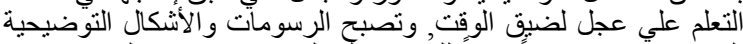

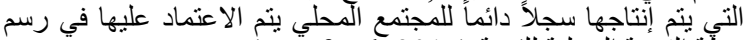

خطُة التنمية المحلية للقرية (Tearfund, 2017).

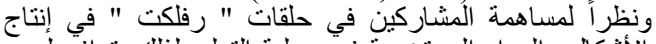

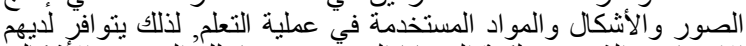

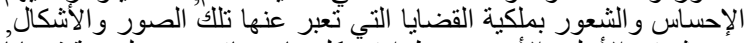

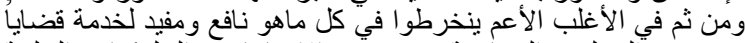

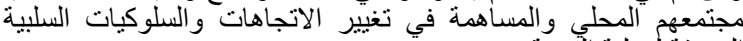
المعوقة لعملية التنمية. في ضوء ما سبق يمكن رصد أهم المرتكزات أو المبادئ التي تقوم عليها

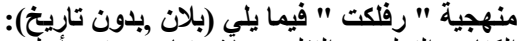

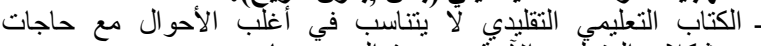

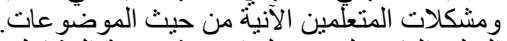

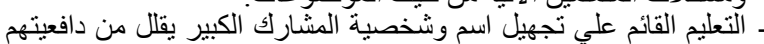
و لا يناسب نضجهم وخبر اتهم. ـ برى " فريري" أن أنتعلم هو (الوعي) ويجب أن أن يساعد الأميين علي

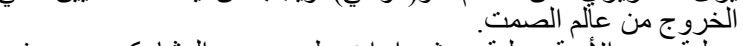

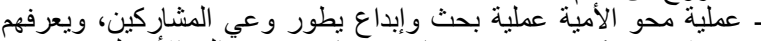

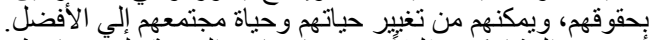

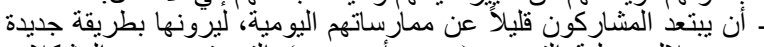

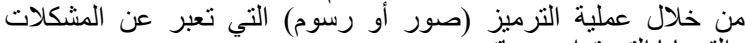
ـ و القضايا التي تو اجه حياتهم. ـ تحليل ألمشكلة بعمق ورؤية الحية الحقيقة بما يتيح للحلقة إحداث فهم جديد

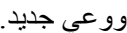
الختيار ها بحرص محو الأمية، و عمليات التحليل، وتعلم الكلمة المولدة التي يتم

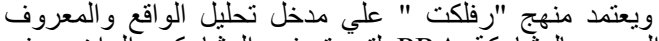

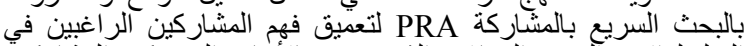
التعلم لو اقعهم الّيومي المعاش والش والذي يهدف بالأساس إلي تمكين المشاركين
برامج التعليم الرسمي في الدول النامبة اسماه "باولو فريرى" بالتعليم

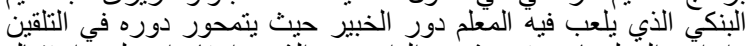

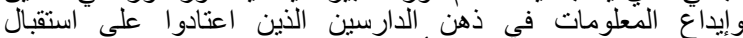

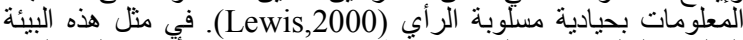

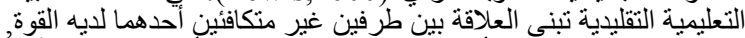

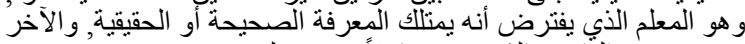

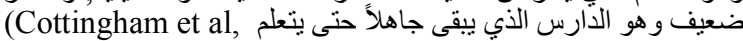

ويعتبر منهج "رفلكت " المساو اة في النو ع الاجتماعي Gender

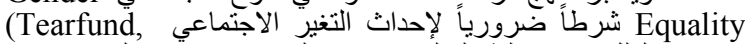

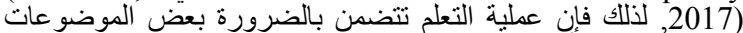

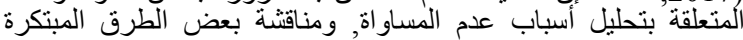

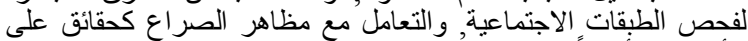

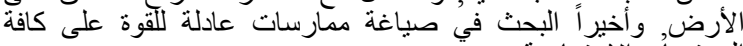
المستويات الاجتماعية.

وقد بدأت منهجية " رفلكت " في التطبيق للمرة الأولى في ثلاث

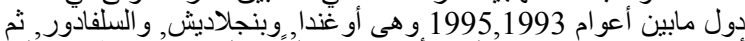

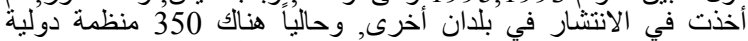
تستخدم هذه المنهجية وتنطبقها في 60 دولة حولة حول العالم (بلان , بدون

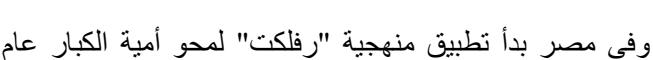
تاريخ).

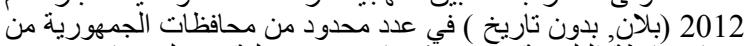

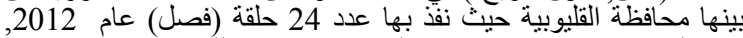
68 حلقة عام 2013, و عدد 83 حلقة عام 2014 وذللك في عدد محدود من

وبطبيعة الحال فإن اختبار منهجية "رفلكت " للتعلم بالمشاركة

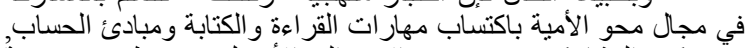

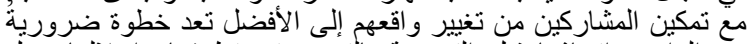

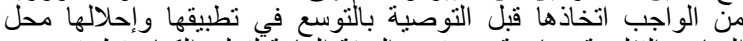

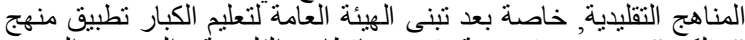

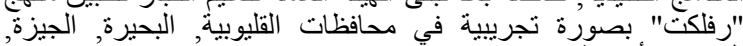

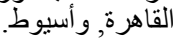

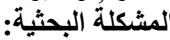

تبلورت مشكلة الدراسة في محاولة الإجابة على التساؤل التالي

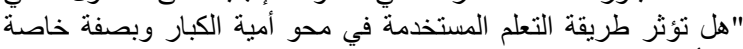

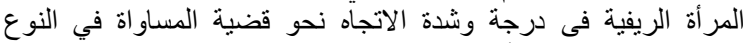

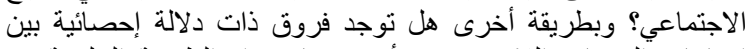

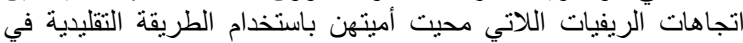

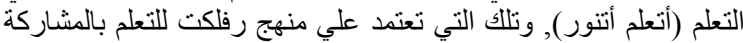

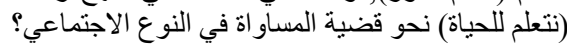

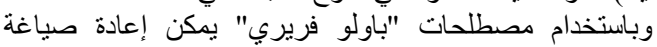

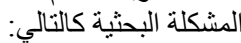

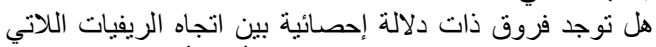

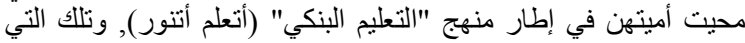

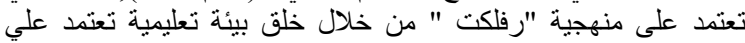

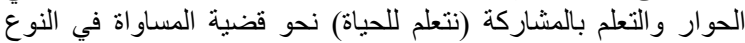

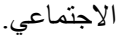

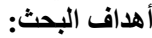

يُنتهذف البحث بصفة أساسية التعرف على أثر اختلاف المناهج

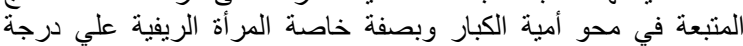
الاتجاه نحو قضية المساو اة في النوع الاجتماعي. وبصورة أكثر تفصيلاً يمكن صياغة أهداف البحث في الأتي:

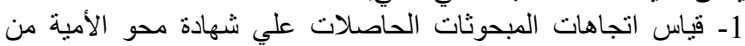

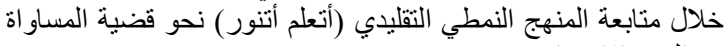
في النوع الاجتماعي. 2- قياس اتجاهات التّبحوثات الحاصلات المات علي شهادة محو الأمية من

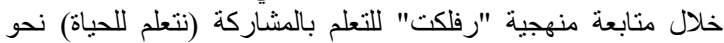
قضية المساو اة في النوعة الاجتماعي.

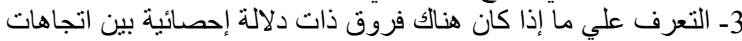

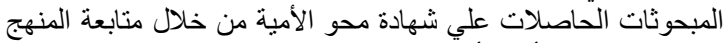

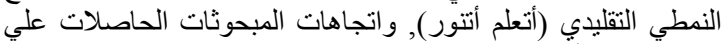

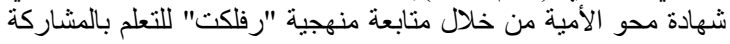
(نتعلم للحياة) نحو قضية المساو اة في النو ع علانية الاجتماعي.

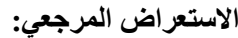


طرق للتفكير و التدبر تساهم أو تساعد في تحقيق أو بلوغ الهدف المنشود

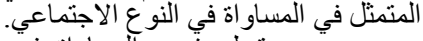

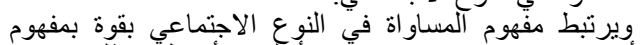

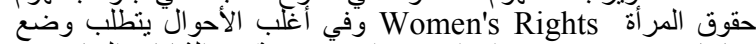
سياسات محفزة تستهدف إحداث تغير ات جوهرية في الثقافات السائدة في

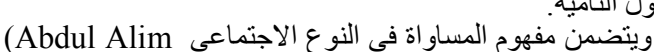
معظم الدول النامية.

et al, 2005)

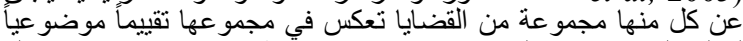

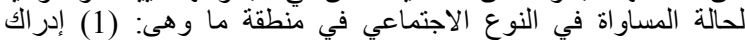

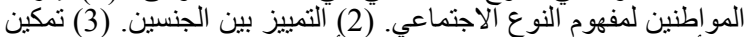

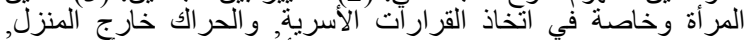

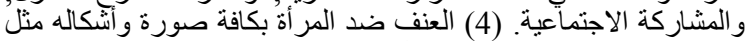

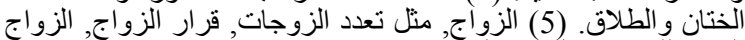

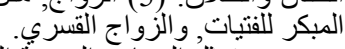

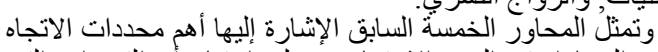

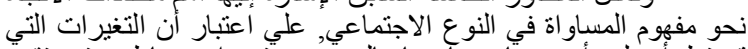

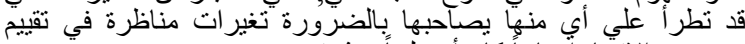
موضوع الاتجاه أيجابياً كان أح سلبياً, وشدته.

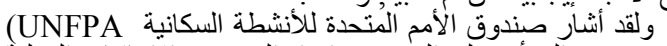
- Wikipedia)

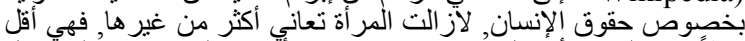

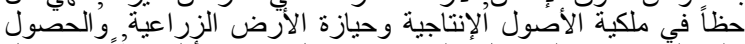

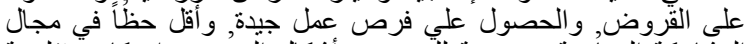

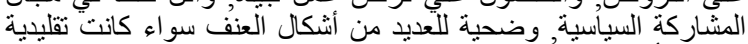
موروثنة أو مستحدثنة. فروض البحث:

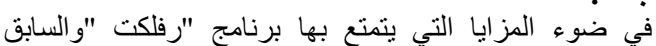

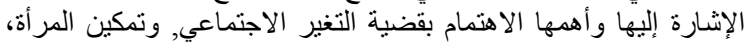

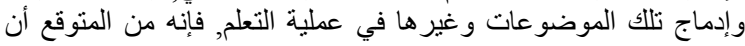

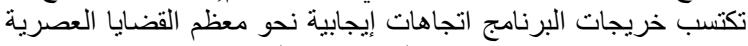

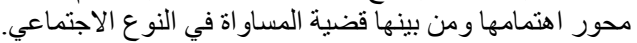

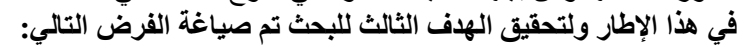
الفرض الصفري Ho

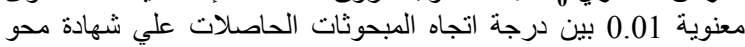

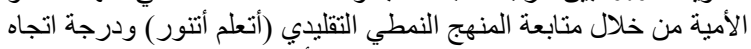

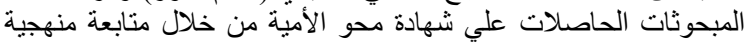
"رفلكت" للتعلم بالمشاركة (نتعلم للحباة) نحو قضية الأنية المساواة في النوع

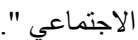

الفرض البديل H1 :

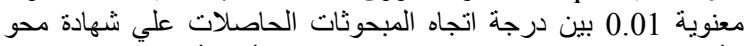

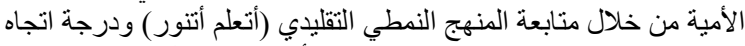

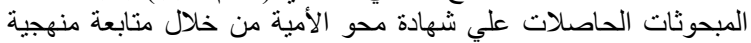

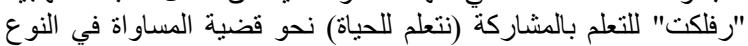

\section{الطريقة البحثية}

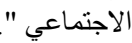

اعتمد البحث علي المنهج الوصفي التحليلي بهدف إلقاء الضوبه

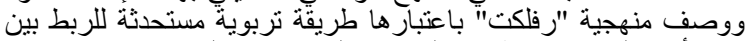

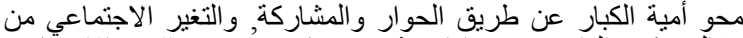

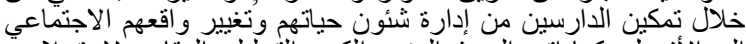

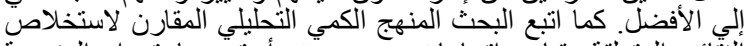

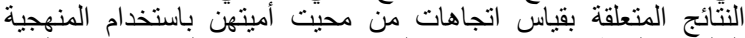
التقليدية النمطية, ومنهجية "رفلكت" نحو قضية المساواة في النوع

الاجتماعي.

المجال الجغرافي لعينة البحث: البئ

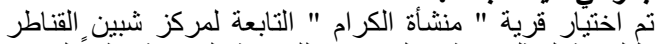

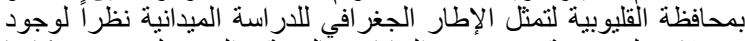

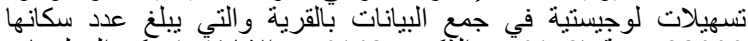

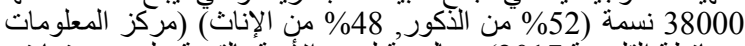

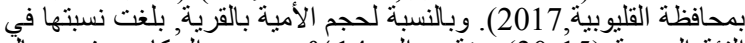

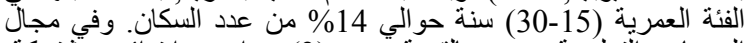

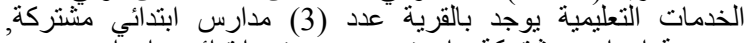

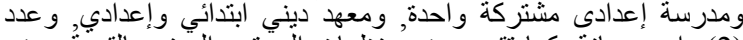

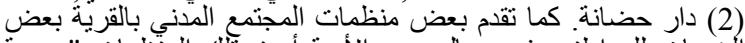

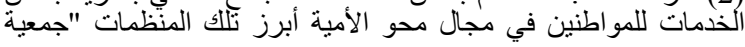

من إمكانياتهم وقدر اتهم للوصول إلي التفكير في تغيير و اقعهم للأفضل,

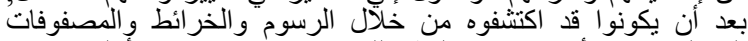

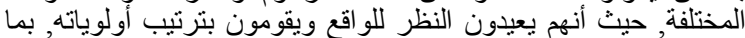
يتتاسب مع احتياجاتهم (Vishwanath, 2006). ويعد منهج "رفائه (رلكت " من أنجح المناهج في الربط بين عملية

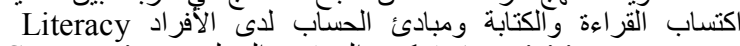
Community وتمكين المجتمع المحلى ولئئAcquisition Process Empowerment المر أة, لتأمين حقوقها الأساسية (Lewis, 2000)

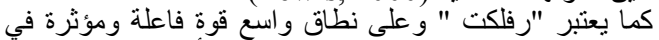

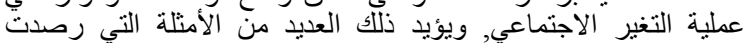

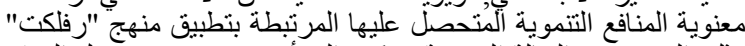

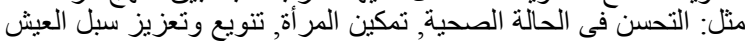

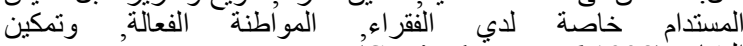
الفتيات (Cottingham et al,1998).

(Abdul ولقد برهنت بعض الدراسات و البحوث المقارنة) فاعلية Alim et al, 2005), (Finnish refugee council, 2016) وجدوى منهج " رفلكت " مقارناً بغيره من مناهج التعلم التقليدية الأخرى

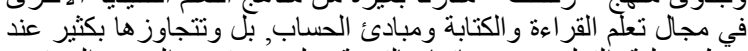

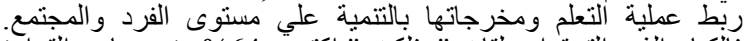

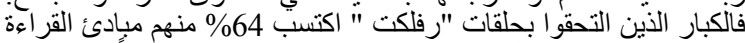

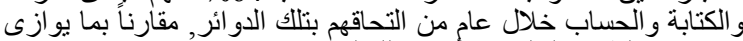

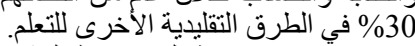

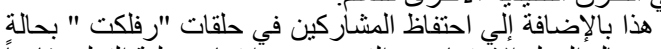

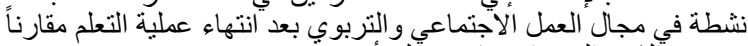

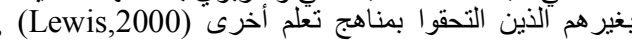

(Tearfund,2017), (Finnish Refugee Council 2016)

منافع وفوائد تطبيق منهج رفلكت علي المشاركين: Abdul Alim) et al ,2005)

- بيسنطيع المشاركون الحديث عن أنفسهم بصورة أفضل, فيها قدر أكبر من إكنا

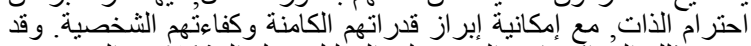

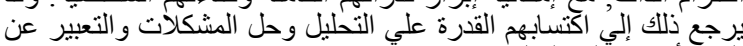

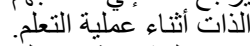

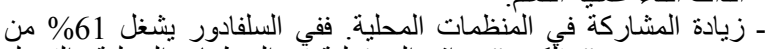

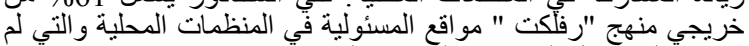

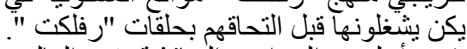

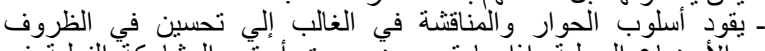

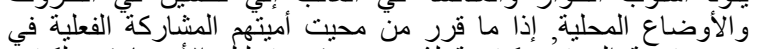

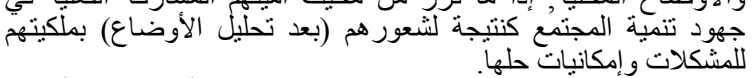

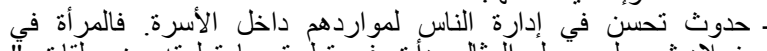

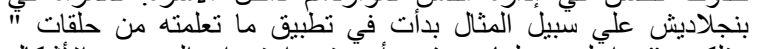

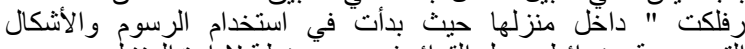

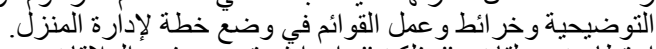

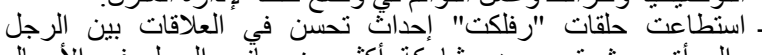

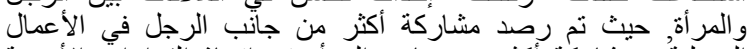

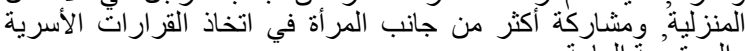

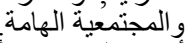

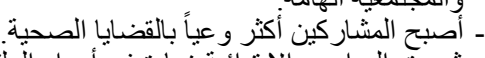

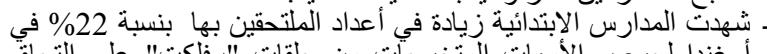

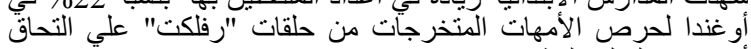

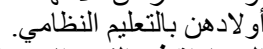

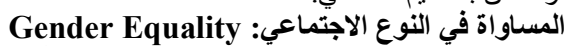

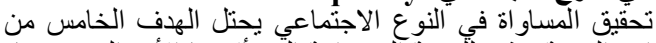

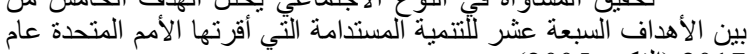

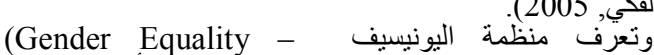
2017 (الفكي, 2005).

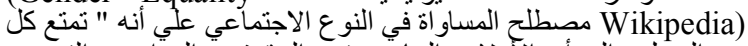

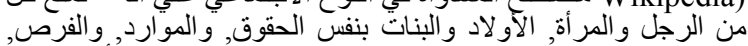

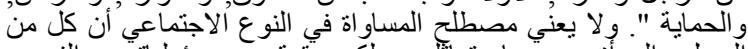

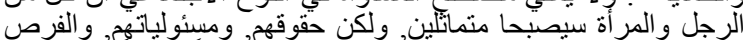

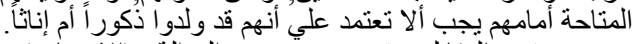

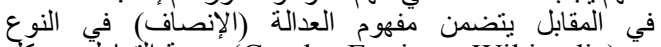

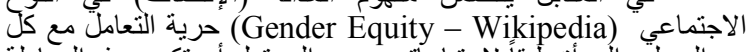

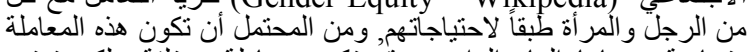

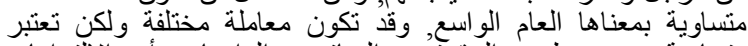

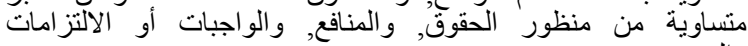

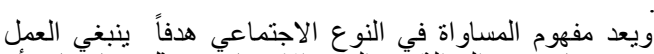

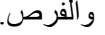

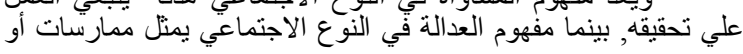




\section{Jacinthe I. Rihan}

بالقرية، بدعم فني من منظمة " بلان انترناشيونال - مصر " وحصلن العني

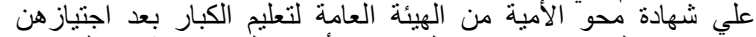

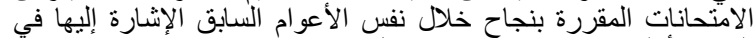

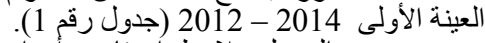
ومن الجدول يلاحظ انخفاض أعداد الناجحين مقارنة بأعداد

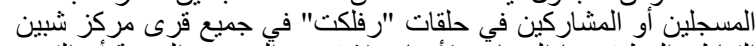

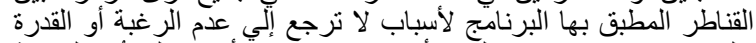

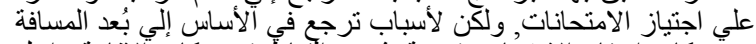

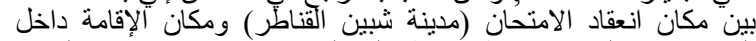

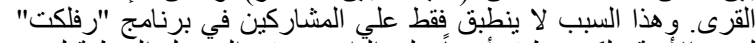

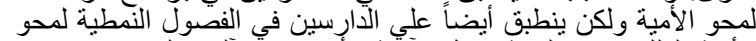

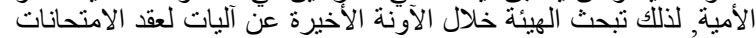

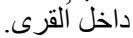

تنمية المجتمع المحلي" بقرية "منشأة الكرام" المشهرة تحت رقم 46 لسنة

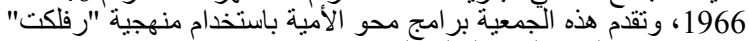

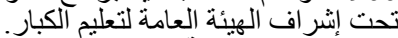

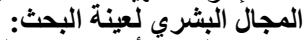

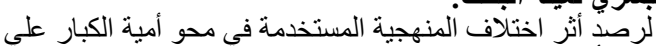

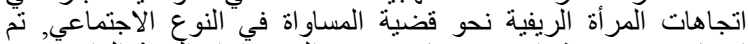

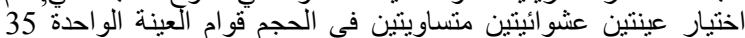

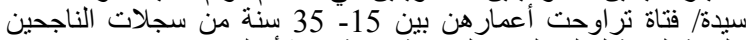

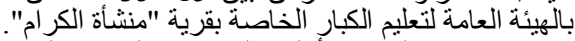

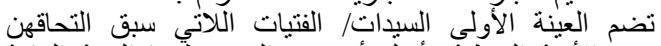

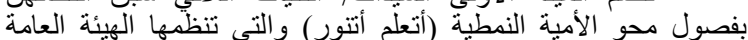

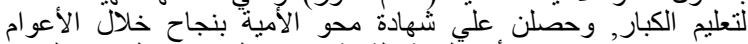

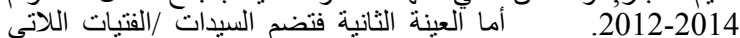

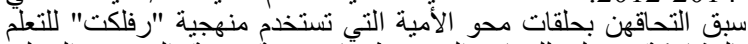

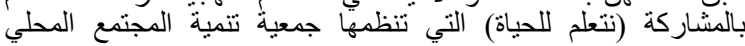

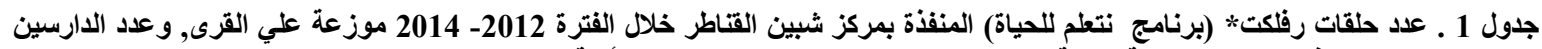

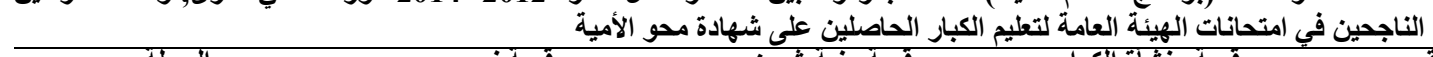

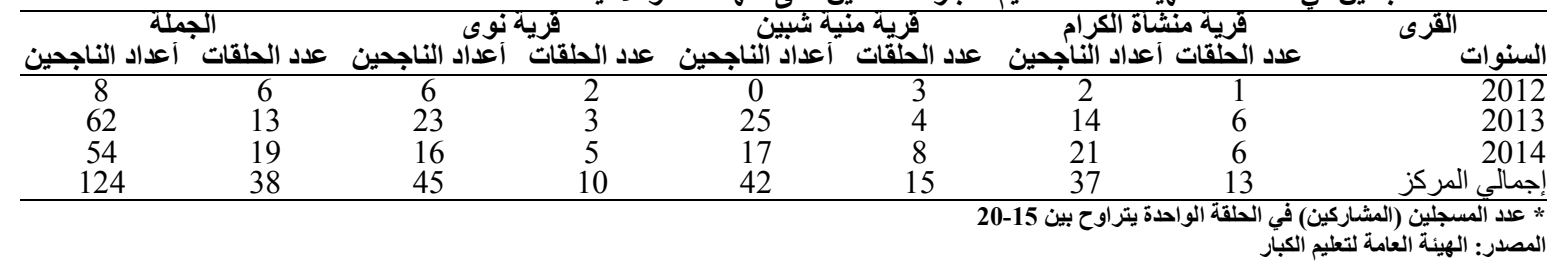

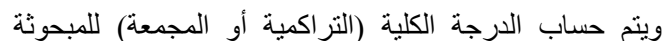

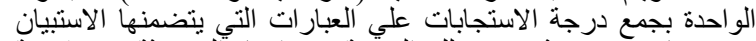

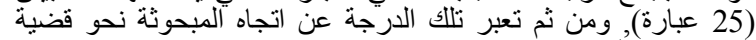

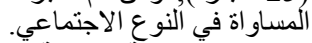
المفاهيم الإجرائية وطريقة الأقياس:

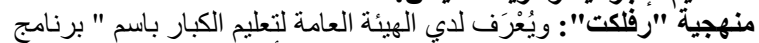

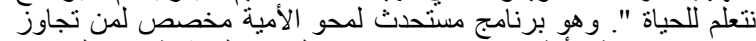

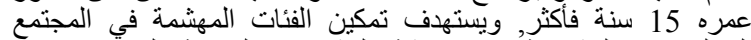

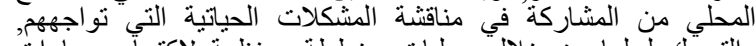

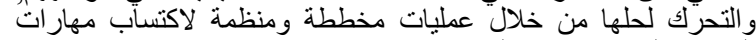
القز اعة والكتابة ومبادئ الحساب.

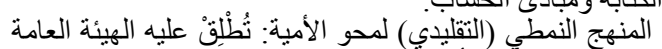

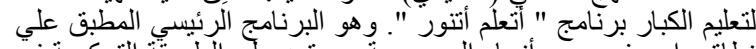

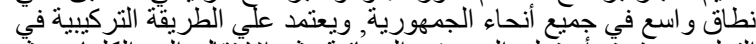

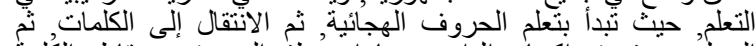

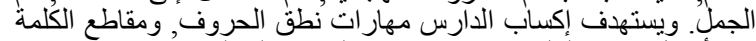
مجز أة قبل وضع الكلمات بجوار بعضئ الار بها لتكوين الجملة (بغداد, 2001).

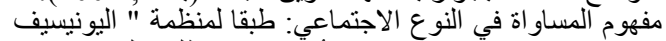

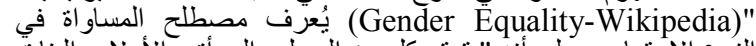

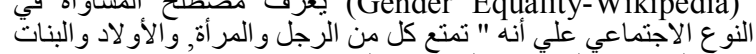

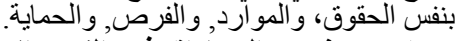

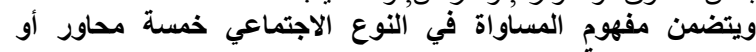

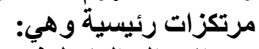

(1) الإدراك العام لمفهوم النوع الاجتماعي: ويشتمل علي ثلاثة قضايا:

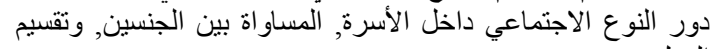

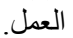

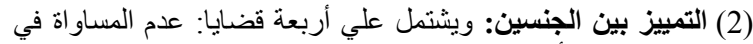

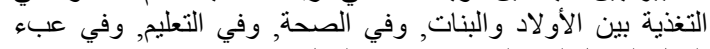

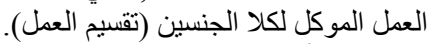

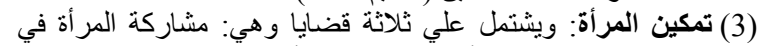

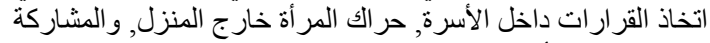

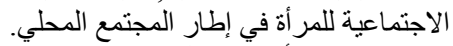

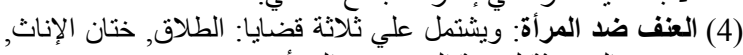

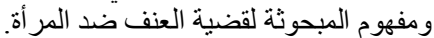

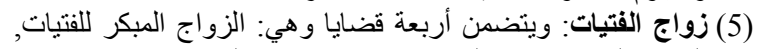

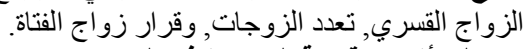

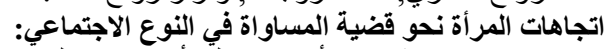

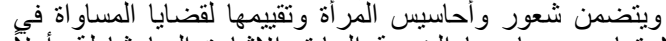

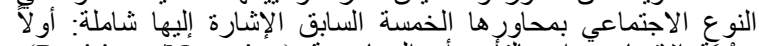

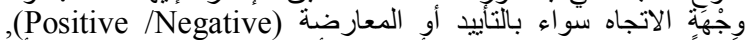

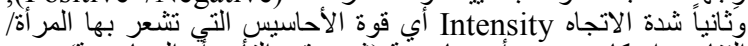

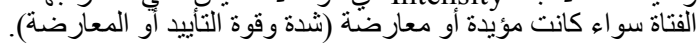

لمجال الزمني للبحث:

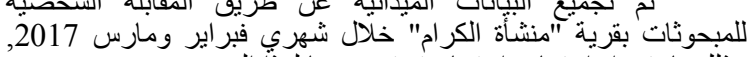

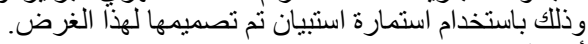

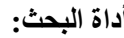

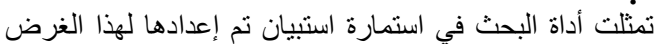

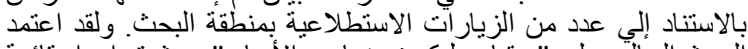

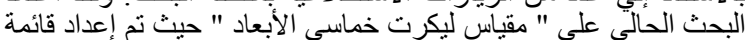

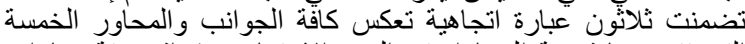

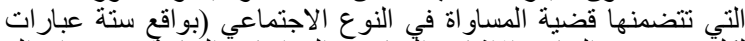

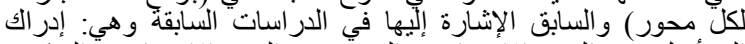

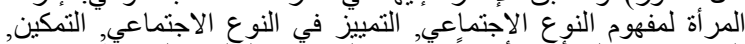

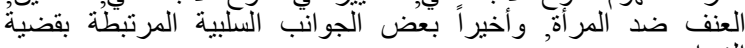

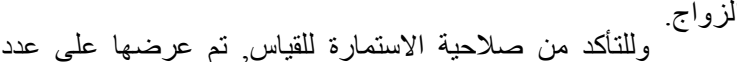

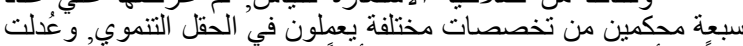

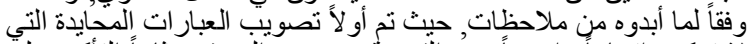

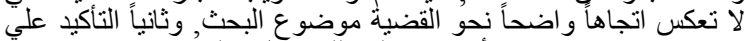

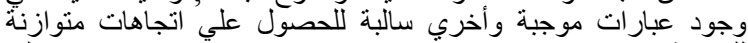

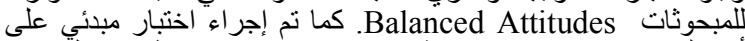

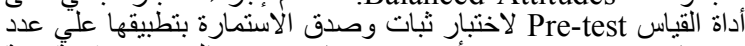

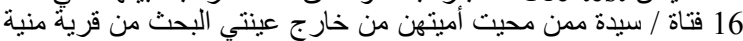

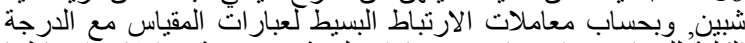

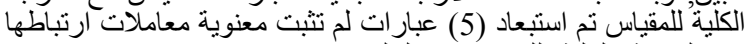

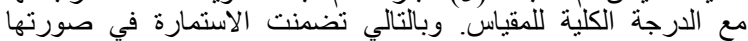

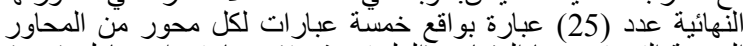

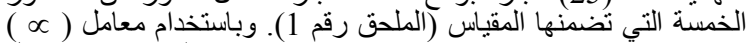
"Reliability Analysis-Scale (ALPHA)" الثبات 0.8621 و هي قيمة مقبولة إحصائياً وتدل علي ثبات المقياس. كما

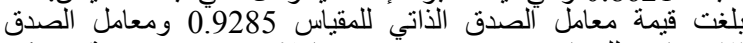
الإحصائي للمقياس 0.9512 ووهي معاملات لإنيات صدق مرتفعة ويمكن

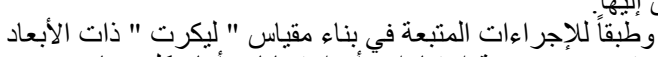

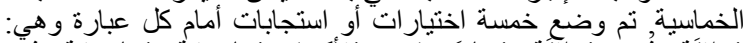

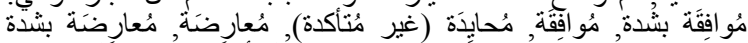

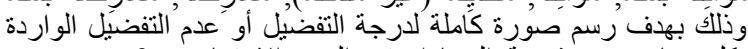

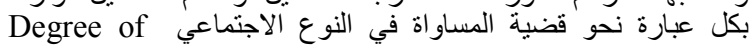
.Favorableness or Unfavorableness

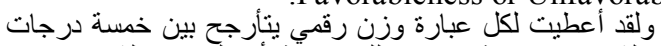

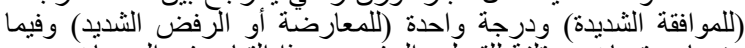

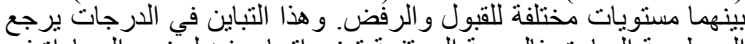

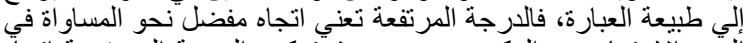

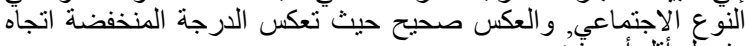


نموذج التحليل: الثكل رقم (1) الإطار التحليلي للبحث ويتضمن الأبعاد

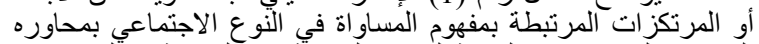

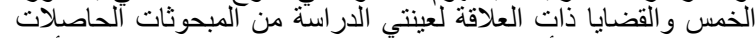

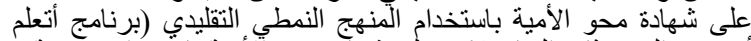

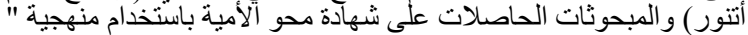
رفلكت " للتعلم بالمشاركة (برنامج نتعلم للحياة).
أدوات التحليل الإحصائي:

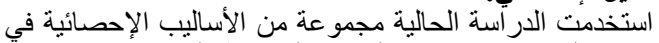

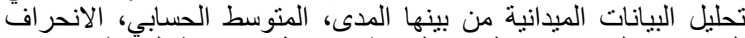

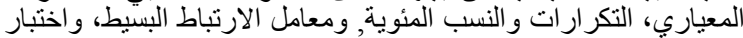

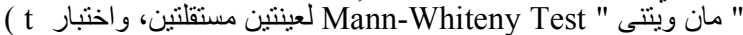

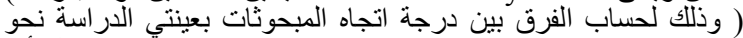
قضية المساو اة في النوع الاجتماعي، بالإضافة إلى استخدام معامل ألى ألفا Reliability Analysis-Scale (ALPHA)

الاتجاه موضوع البحث.

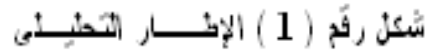

\begin{tabular}{|c|c|c|c|}
\hline \multicolumn{2}{|c|}{ 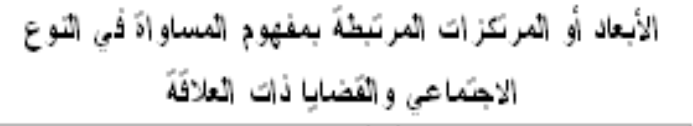 } & \multirow{3}{*}{ 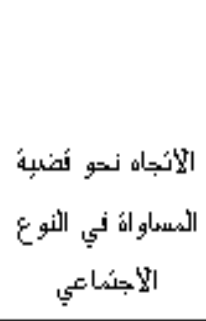 } & 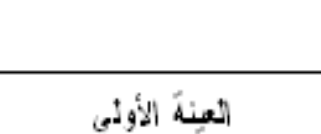 \\
\hline 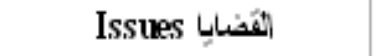 & Themes الهداور & & \multirow{3}{*}{ 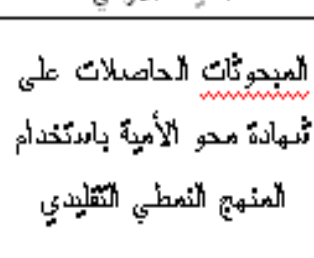 } \\
\hline 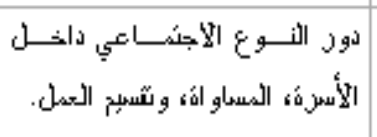 & 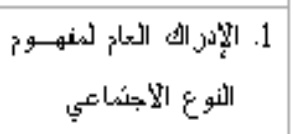 & & \\
\hline 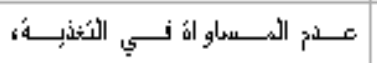 & \multirow[t]{2}{*}{ 2. النَبيز ببن الجنسبن } & \multirow{7}{*}{ 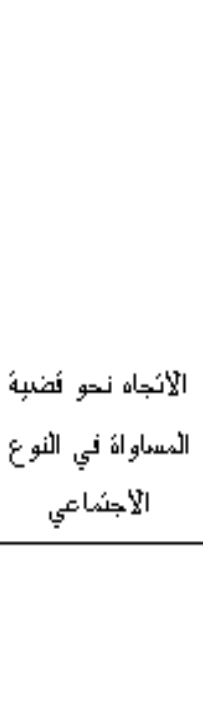 } & \\
\hline 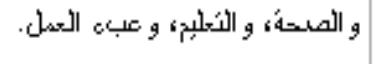 & & & برناميح: أُعْم أُتْور \\
\hline 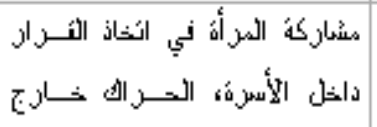 & \multirow[t]{2}{*}{ 3. نككن المرأة } & & \\
\hline 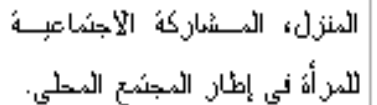 & & & 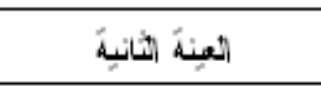 \\
\hline 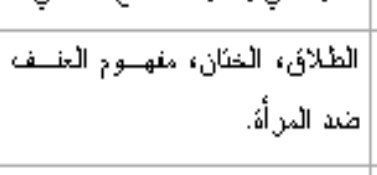 & 4. التنف ضد المرأة & & \multirow{2}{*}{ 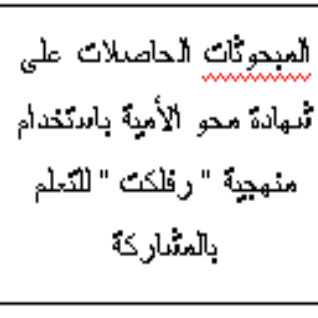 } \\
\hline 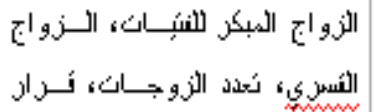 & \multirow[t]{2}{*}{ 5. زو اجي النبَّاك } & & \\
\hline زو اجِ البنتك. & & & 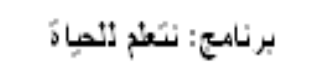 \\
\hline
\end{tabular}

أولاً: اتجاه المبحوثات الحاصلات علي شهادة محو الأمية باستخدام

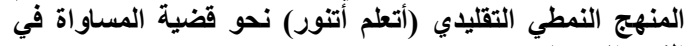

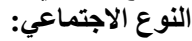
يتضح من النتائج الواردة بالجدول رقم (2) أن الددى الفعلي

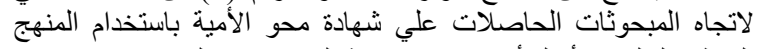

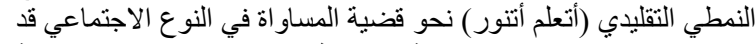

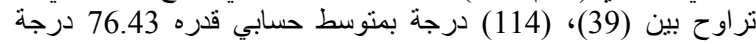

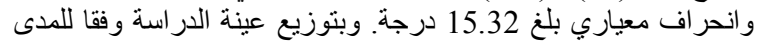
(النظري على الفئات الخمس: معارضة بثدة (25.

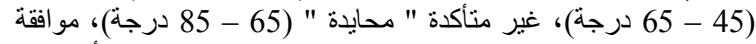

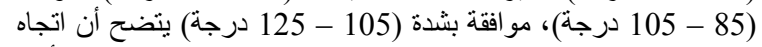

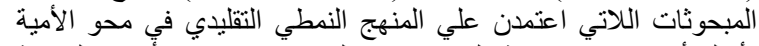

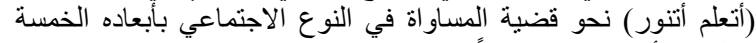

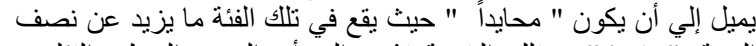

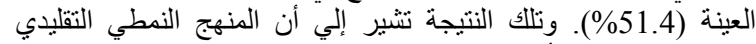
بفلسفته ومحتو ياته وأسلوب تطبيقه لم يتمكن من إدماج القضايا الحياتية في

\section{النتائج والمناقثشات}

اللتعرف على اتجاه المبحوثات نحو قضية المساواة في النوع

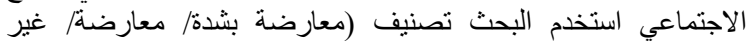

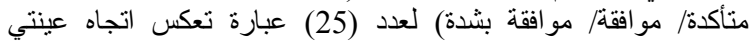

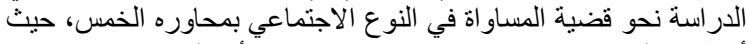
أعطيت الدرجات (1)، (2)، (3)، (4)، (5) (5) أو العكس حسب العباء التجاه

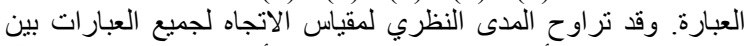

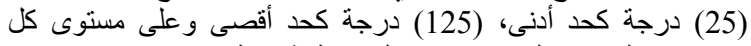

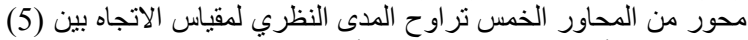

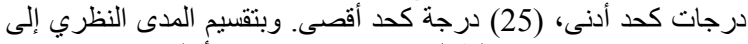

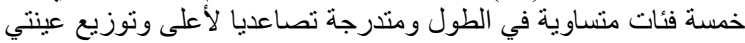

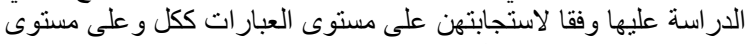
المحاور تشير نتائج التحليل الإحصائي إلى ما يلي: العيار 


\section{Jacinthe I. Rihan}

لديها أن ترى تمييزاً ضدها ولا تتنفض لمقاومته, خاصة وأن هذا

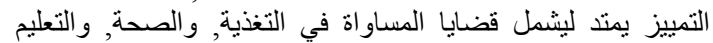

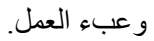

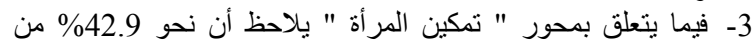

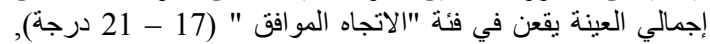
وهو أتجاه إيجابي يعكس رغبة التبة المرأة في المشاركة الاجتماعية,

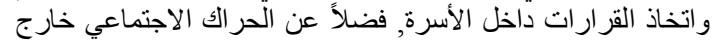

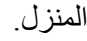

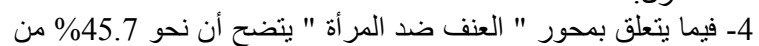

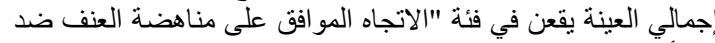

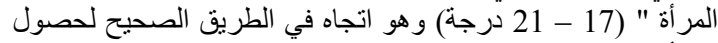

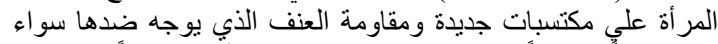

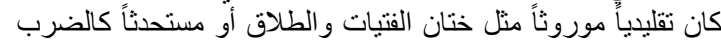
و وغيره من صور العنف المستحدث. 5- فيما يتعلق بمحور " الزواج المبكر و القسري, وتعدد الزوجات " يتبين

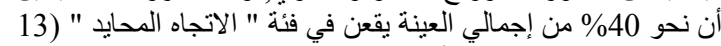

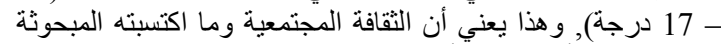

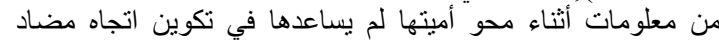
لقضايا الزواج المبكر والقسري، وتعدد الزوجات، فئرين وقرار زواه
عملية التعلم وبصفة خاصة قضايا حقوق المرأة ومن ثم إثارة الوعى الوي

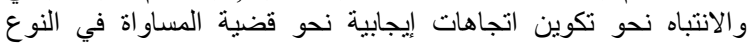

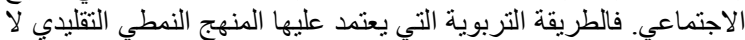

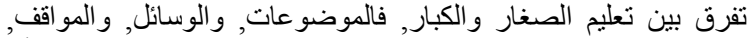

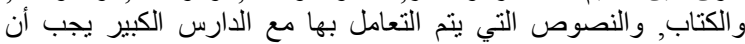

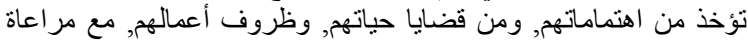

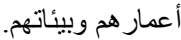
كما يجب أن يتسم الموقف التعليمي بثيء من المرونة, بمعني

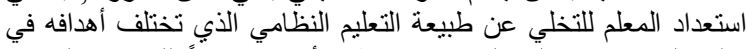

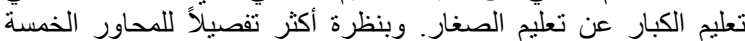
لموضوعات الاتجاه نحو قضية المساواة في النوع الاجتماعي يتضح ما لكاري

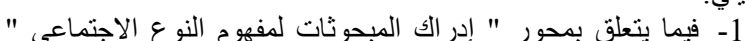
يتضح أن نحو 62.9\% من إجمالي العينة يقعن في فئة " الاتجاه

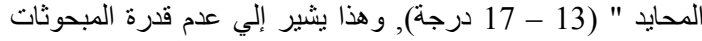

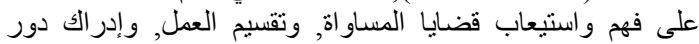
النوع الاجتماعي داخل الأسرة.

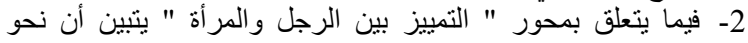

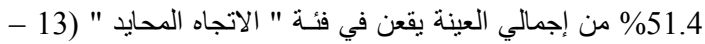

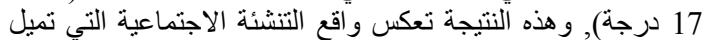
إلي تمييز الذكور عن الإناث داخل الأسرة, ومن ثم فليس هناك غر ابة لتئ

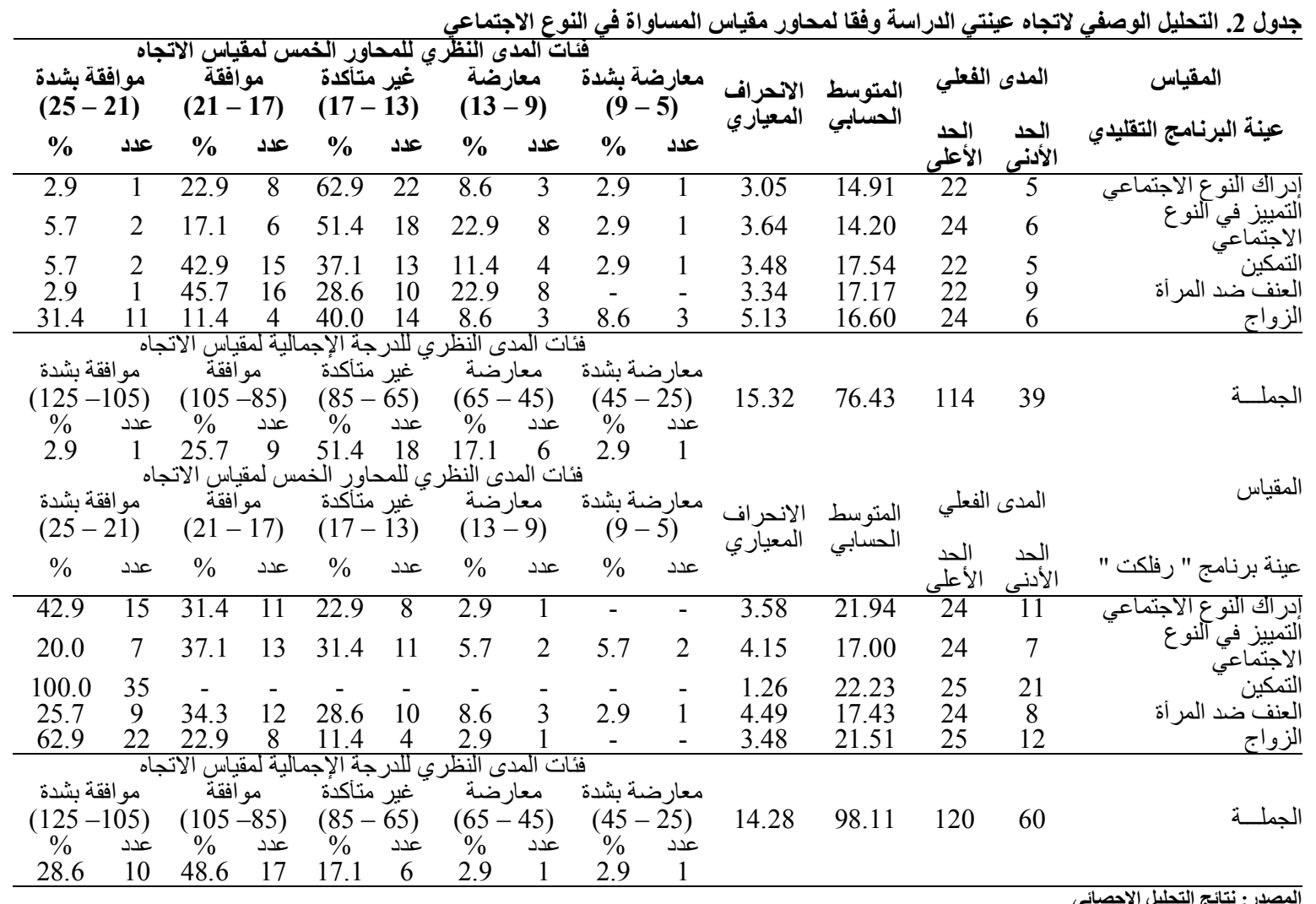

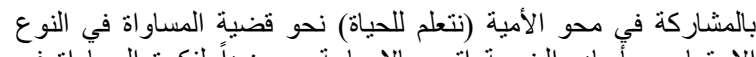

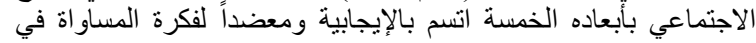

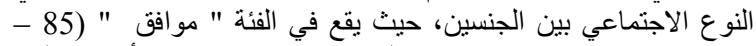

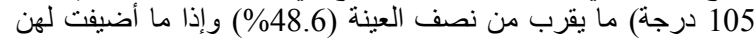

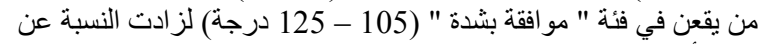

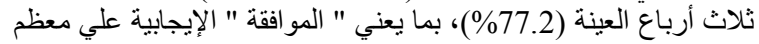

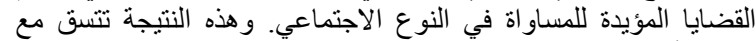

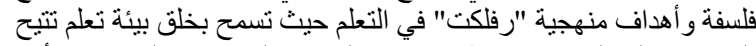

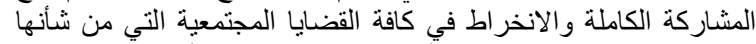

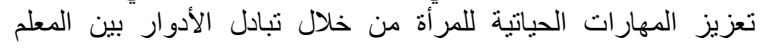

ثانياً: اتجاه المبحوثات الحاصلات علي شهادة بلادئ محو الأمية باستخدام

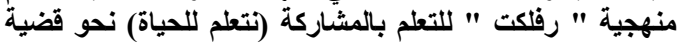
المساواة في النوع الاجتماعي:

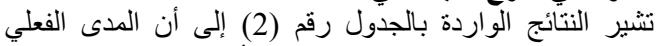

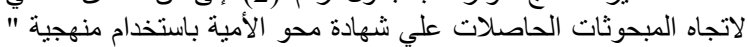

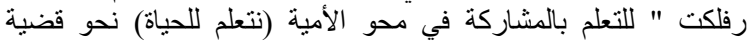

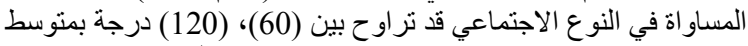

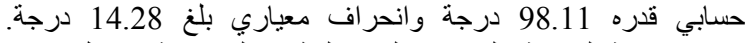

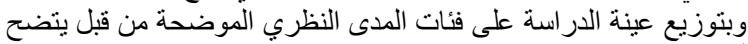
أن اتجاه المبحوثات اللاتي اعتمن علي منهجية " رفلكت " للتعلم 
(ليزلي وآخرون,2011) أن مهارات التعلم تعد المدخل والوسيلة

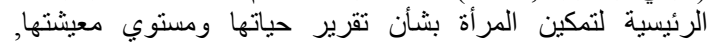

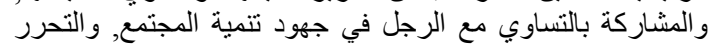

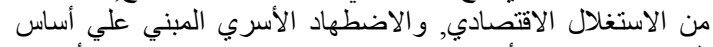

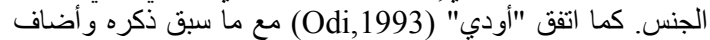

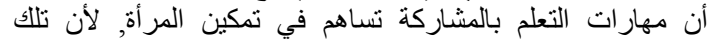

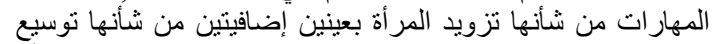

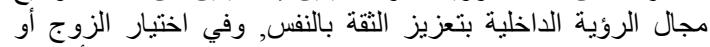

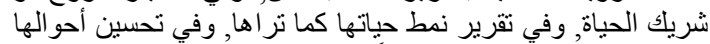

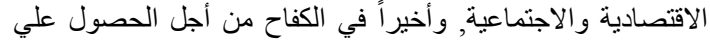
حقوقها و المز ايا المرتبطة بهادها.

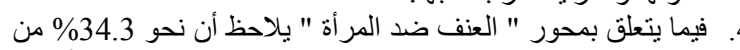

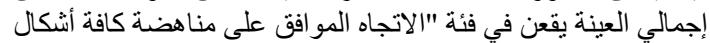

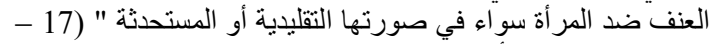

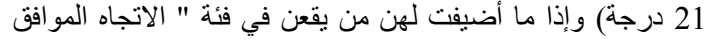

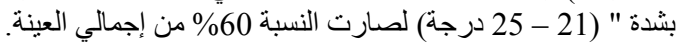

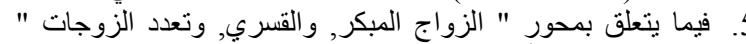

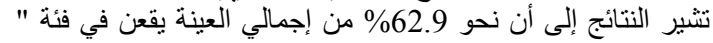

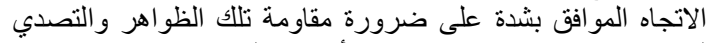

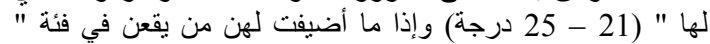

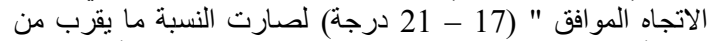

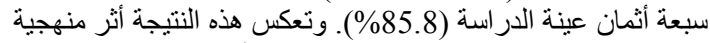

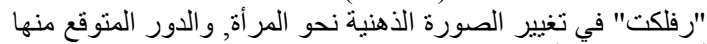

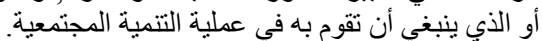

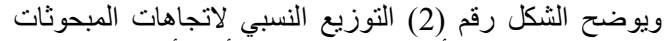

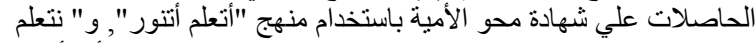

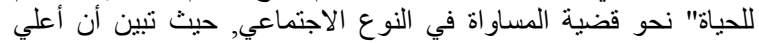

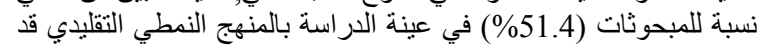

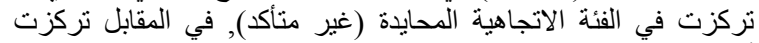

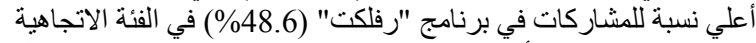

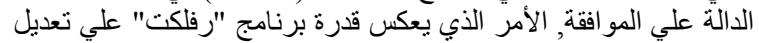

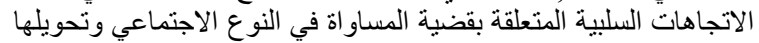

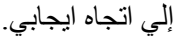

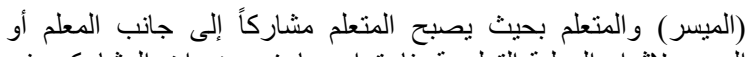

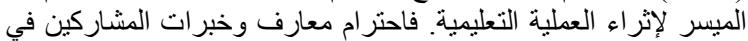

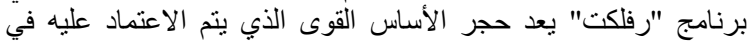

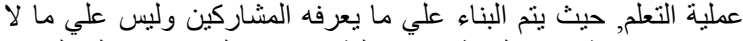

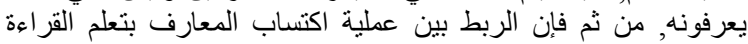

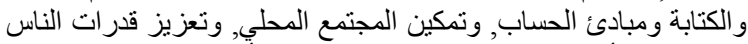

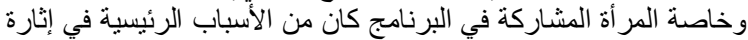

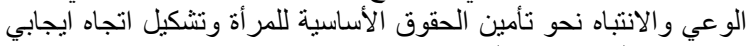

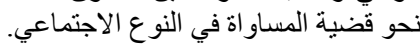

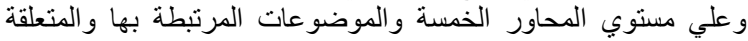

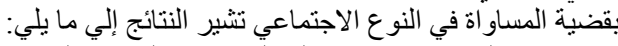

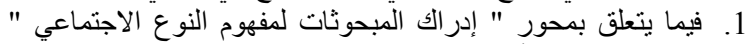

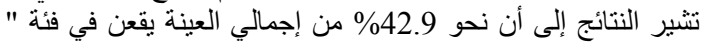

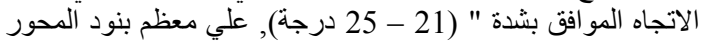

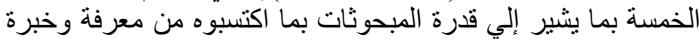

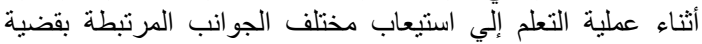

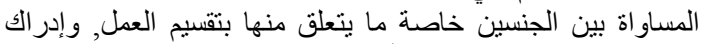
دور النوع الاجتماعي داخل الأسرة.

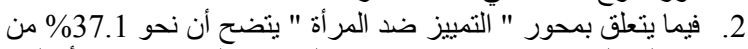

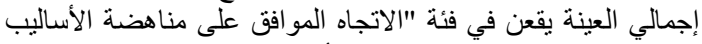

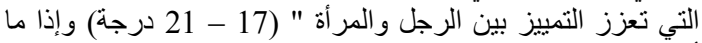

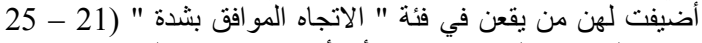

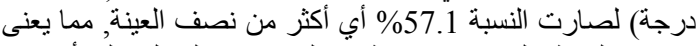

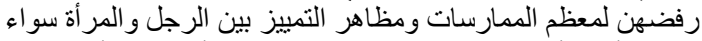
داخل الأسرة أو خارجها خاصة في مجال التعليم أو العمل, أو الصحة الصنة

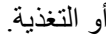

3. فيما يتعلق بمحور " تمكين المرأة " يتبين أن جميع المبحوثات بالعينة

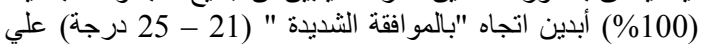

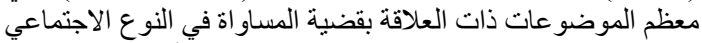

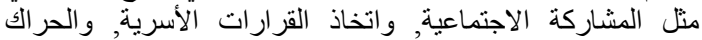

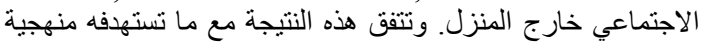

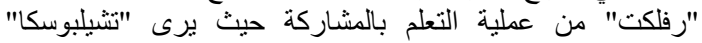
(Chlebowska,1990) و "سيلاو ال" (Silawal,2003) وليزلي بلئي

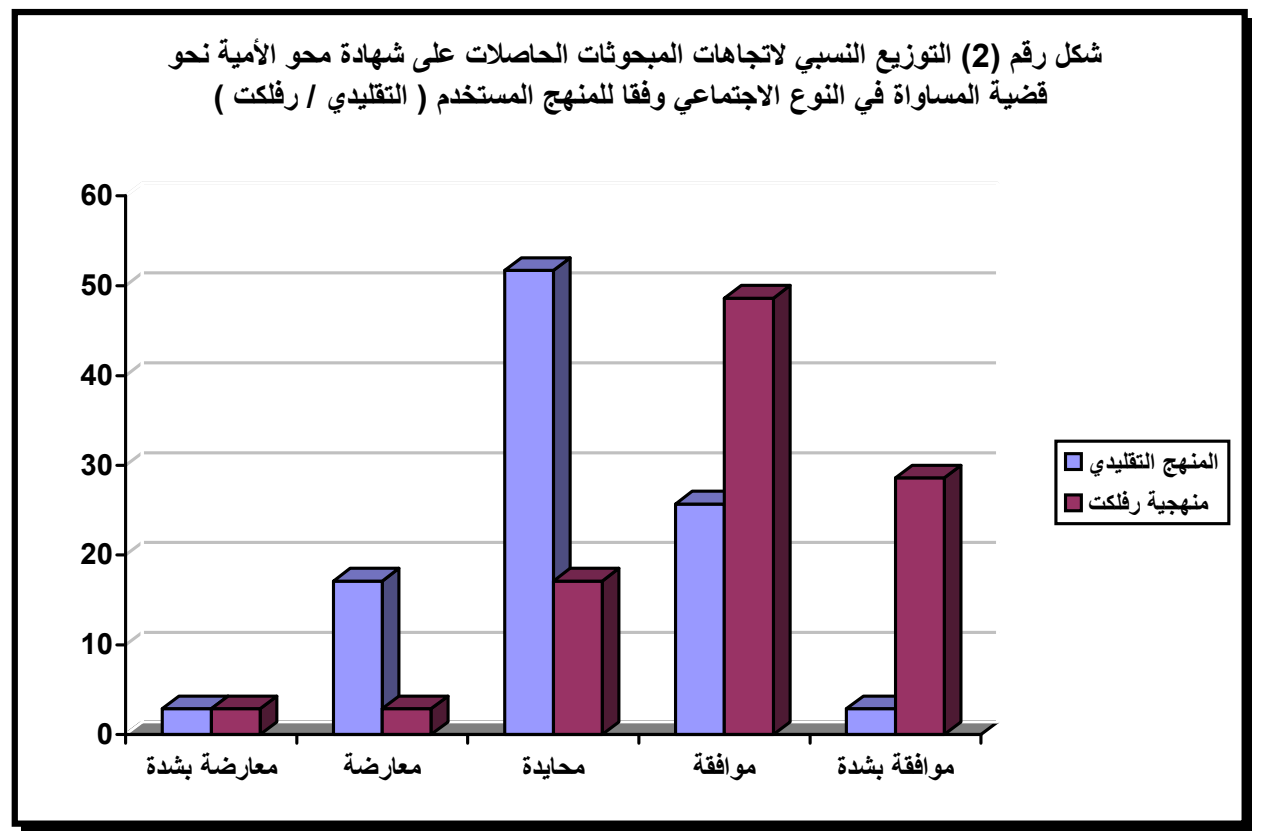

لحساب معنوية الفرق بين منوسط الدرجات المعبرة عن اتجاه

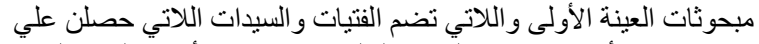

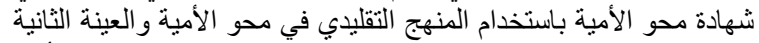

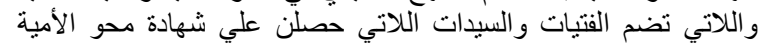

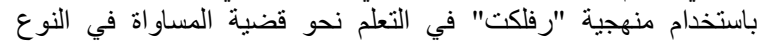

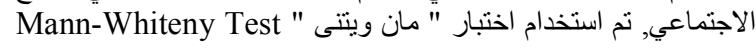

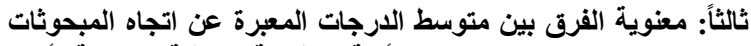
الحاصلات علي شهادة محو الأمية بالطريقة النمطية التقات التليدية (أتعلم المبات

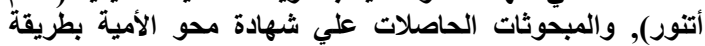

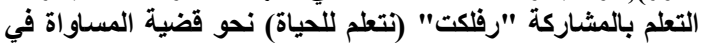

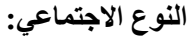




\section{Jacinthe I. Rihan}

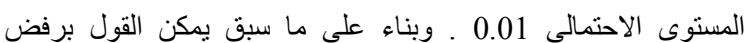

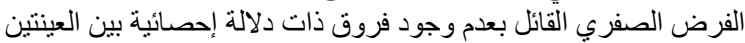

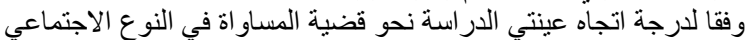
عند مستوى معنوية 0.01, وقبول الفرض البديل.
للفرق بين متوسطي عينتين مستقلتين، حيث بلغت قيمة معامل مان ويتنى 207.5 ( U )

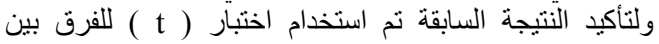
متوسطي عينتين مستقلتين, حيث تشير نتائج التحليل الإحصائي الواردة بالجدول رقم (3) أن قيمة ( t ) المحسوبة بلغت 5.5 و هي معنوية على الإنى

جدول 3. نتائج التحليل الإحصائي للفرق بين متوسطي الارجات المعبرة عن اتجاه المبحوثات نحو قضية المساواة في النوع الاجتماعي بمحاوره

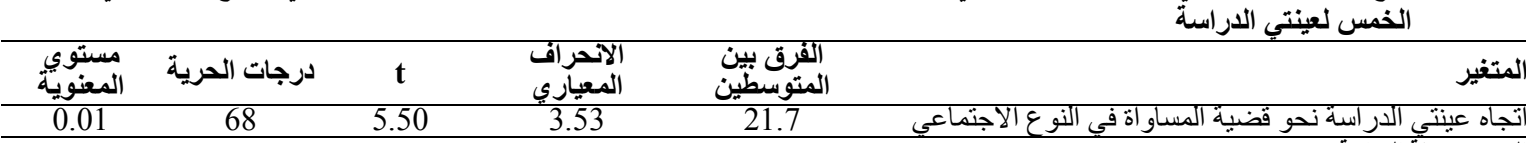

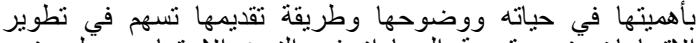

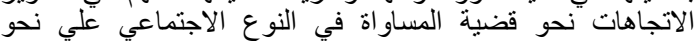
إيجابي.

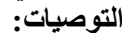

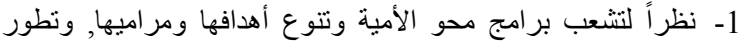

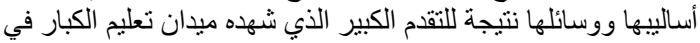

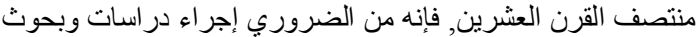

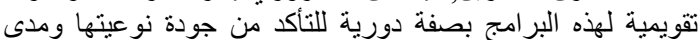

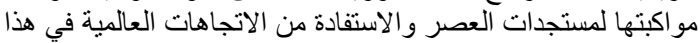

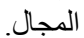

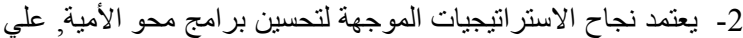

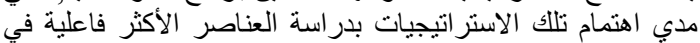

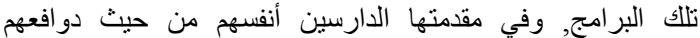

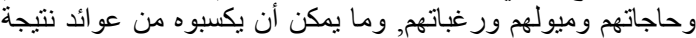

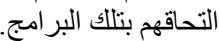

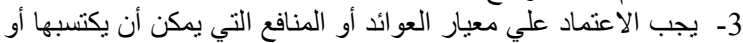

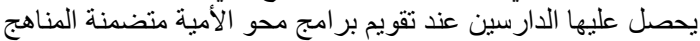

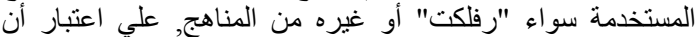

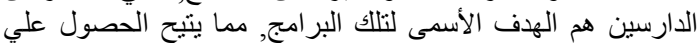

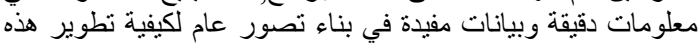
البر امج وتحسينها.

4- التوسع في تطبيق منهجية "رفلكت" في مجال محو أمية الكبار,

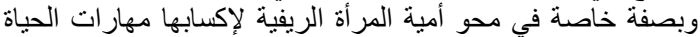
الضرورية إلي جانب اكتساب مهارات القراءة والكتابة ومبادئ

5- إدراج برامج محو الأمية الحضارية في البنية الإنمائية عل الصعيد

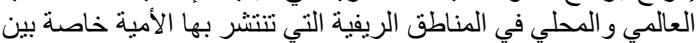
النساء و الفتيات, بوصفها ضرورة تربوية الرية وإنمائية.

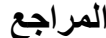

أحمد, أميمه سيد، (2016), المر أة المصرية - حقائق و إنجاز ات, الهيئة

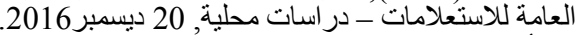

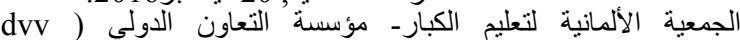
الأردnal

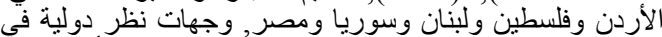

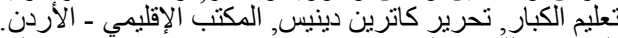
الجهاز المركزي للتعبئة العامة و الإحصاء (2016), نتائج تعداد السكان, الإن

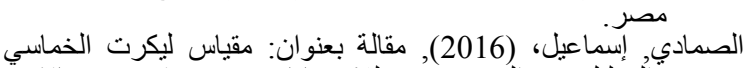

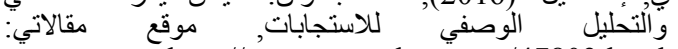
http://www.maqalaty.com/47803.html

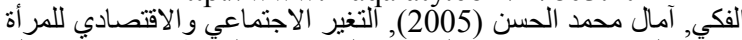

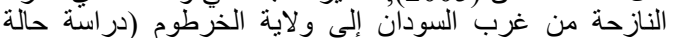

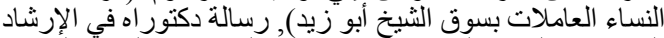

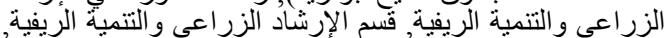

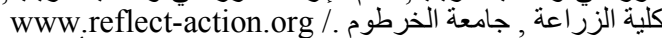
الهيئة العأمة لتعليم ألكبار (2014)، نتائج امتحانة الخرطات محو الأمية في محافظة القليو بية, مصر.

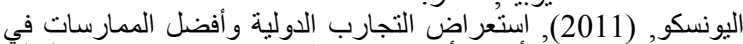

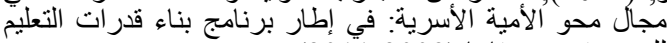

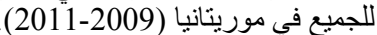

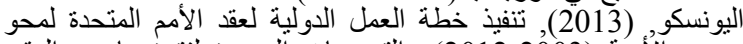

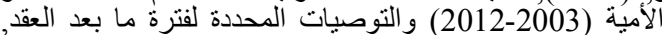

المؤتمر العام- الدورة السابعة والثنالثون, باريس 7-11-2013.
إن خدمات وبر امج محو الامية التقليدية في مصر لاز الت فاصرة

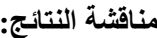

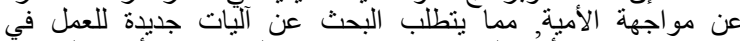

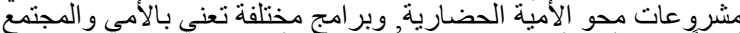

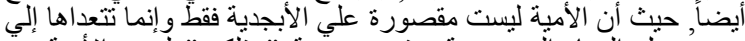

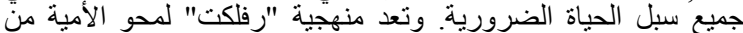

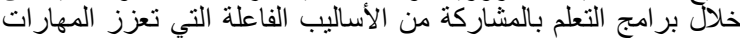

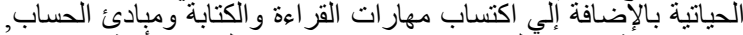

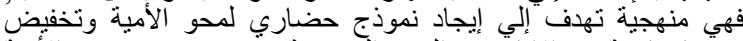

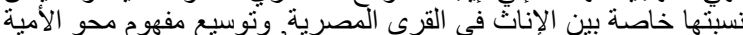

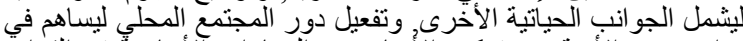

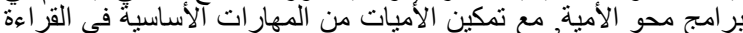

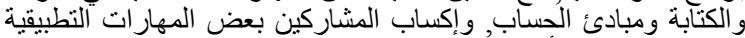

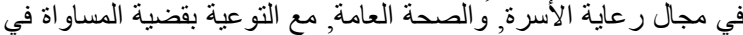
النّوع الاجتماعي.

وفي ضوء النتائج المتحصل عليها و التي أوضحت تميز و إيجابية

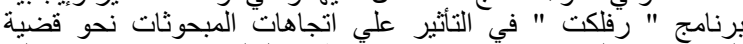

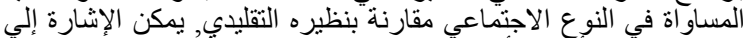

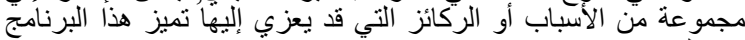

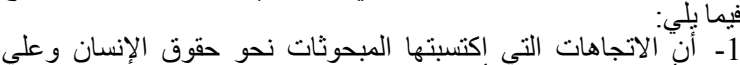

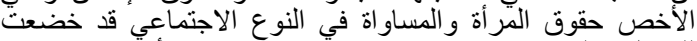

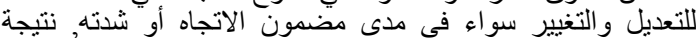

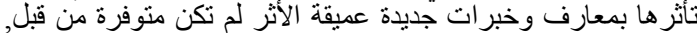

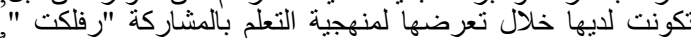

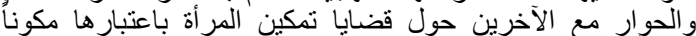

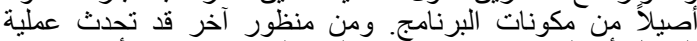

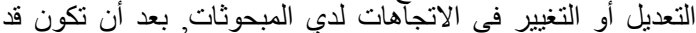

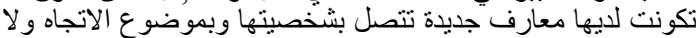
تكون منو افرة قبل ذللك. وقد يكون العامل الرئيسي في تغير التئ الاتجاه

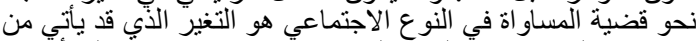
نمو و عي المبحوثات, و التغير المصاحب في تغير النير حاجات المر أة نحو الحفاظ علي حقوقها.

2- ترجع الاتجاهات الإيجابية التي تكونت لدي المبحوثات اللاتي مُحيت الماتي

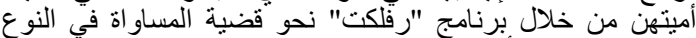

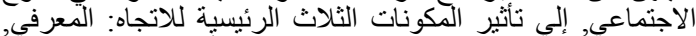

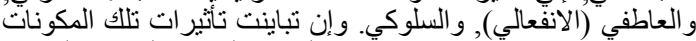

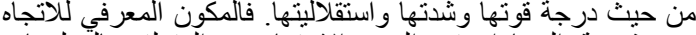

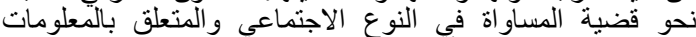

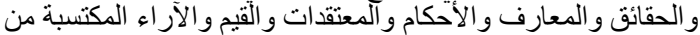

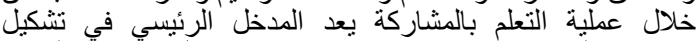

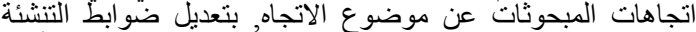

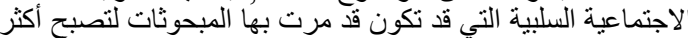

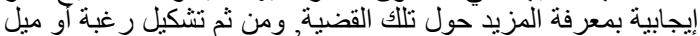

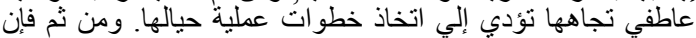

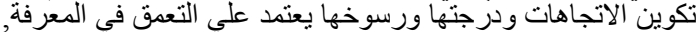

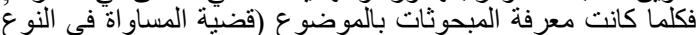

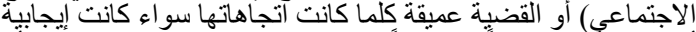

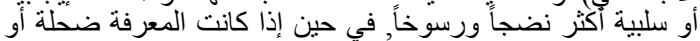
سطحية كانت الاتجاهات غير ثابتةً ويمكن تغير ها بحسب الخبر الخبرة التي

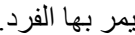
3- يستهدف مكون الثقافة العامة في محو أمية الكبار في برنامج "رفلكت

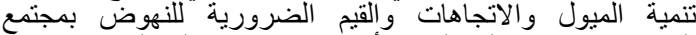

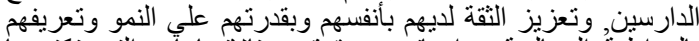

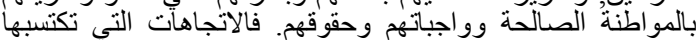

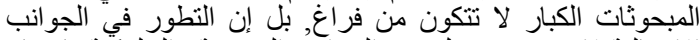

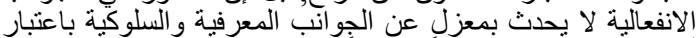
أن هذه الجوانب تشكل كلاً متكاملاً, فاكتساب المعرفة وشعور المتعلم 


\section{J. Agric. Econom. and Social Sci., Mansoura Univ., Vol.8 (11), November,2017}

Finnish Refugee Council (FRC), (2016), Adult Literacy REFLECT Training Manual, Sierra Leone, Programme, May 2016.

Gender Equality- Wikipedia.

Gender Equity- Wikipedia

Lewis, J. (2000), "Learning to Relearn Givens ", Participatory Learning And Action (Pla) Notes 37, London: International Institute For Environment And Development (ILED).

Odi, V.J. (1993), An Education of The Literacy Component Of The Better Life Program For Rural Women In Ohaozara Local Government, Nuskka.

Silawal B. (2003), Literacy, Education and Women's Empowerment, Literacy And Non- Formal Education Division Of Basic Education, UNESCO.

Tearfund, (2017), REFLECt - A PLA approach to literacy, England\& Wales.

UNFPA - Wikipedia

UNISA (University of South Africa), (2014), Teaching literacy to Adults- ABT 1517, Department Of Adult Basic Education And Youth Development, South Africa.

Vishwanath, Tara, (2006), Country Gender Assessment (CGA) Report for Pakistan, World Bank, Washington, DC.
باولو فريري، (2002), نظرات في ثربية المعذبين في الأرض, دار

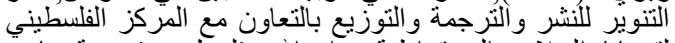

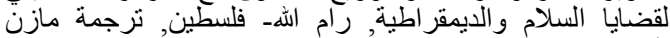

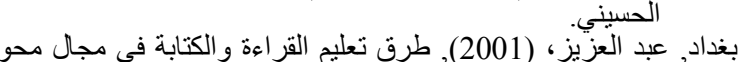

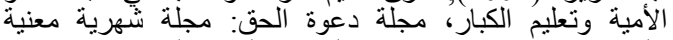
بالدراسات الإسلامية وبشئون التقافة و الفكر, العدد 359, يونية دئية

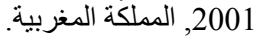
بلان، (بدون تاريخ), برنامج نتعلم للحياة: الدليل الإجرائي, هيئة بلان

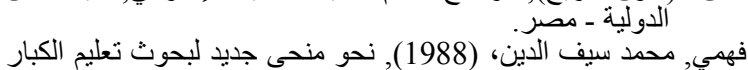

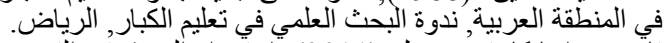

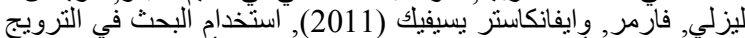

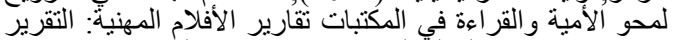
رقم 130, الاتحاد الدولي لجمعيات ومؤسسات لئسات المكتبات. مركز المعلومات بمحافظة القليوبية, (2017), (2017), مصرئ

Abdul Alim Md. and Ahmed Tareq Rashid (2005), Building positive Attitudes Towards Gender Equality: A Baseline Survey Of Gender Quality Action Learning Programme, Brac Research Report, Brac Research And Evaluation Division, Brac Center, Dhaka, Bangladesh.

Chlebowska, K. (1990); Literacy For Rural Women in Third Word, Unesco, Paris.

Cottingham, Sara, Kate Metcalf and Bimal Phnuyal, (1998), The reflect Approach to Literacy And Social Change: A Gender Perspective, Gender And Development Journal/ vol 6, no.2, jul.1998. Taylor \& Francis, Ltd, Jstor.

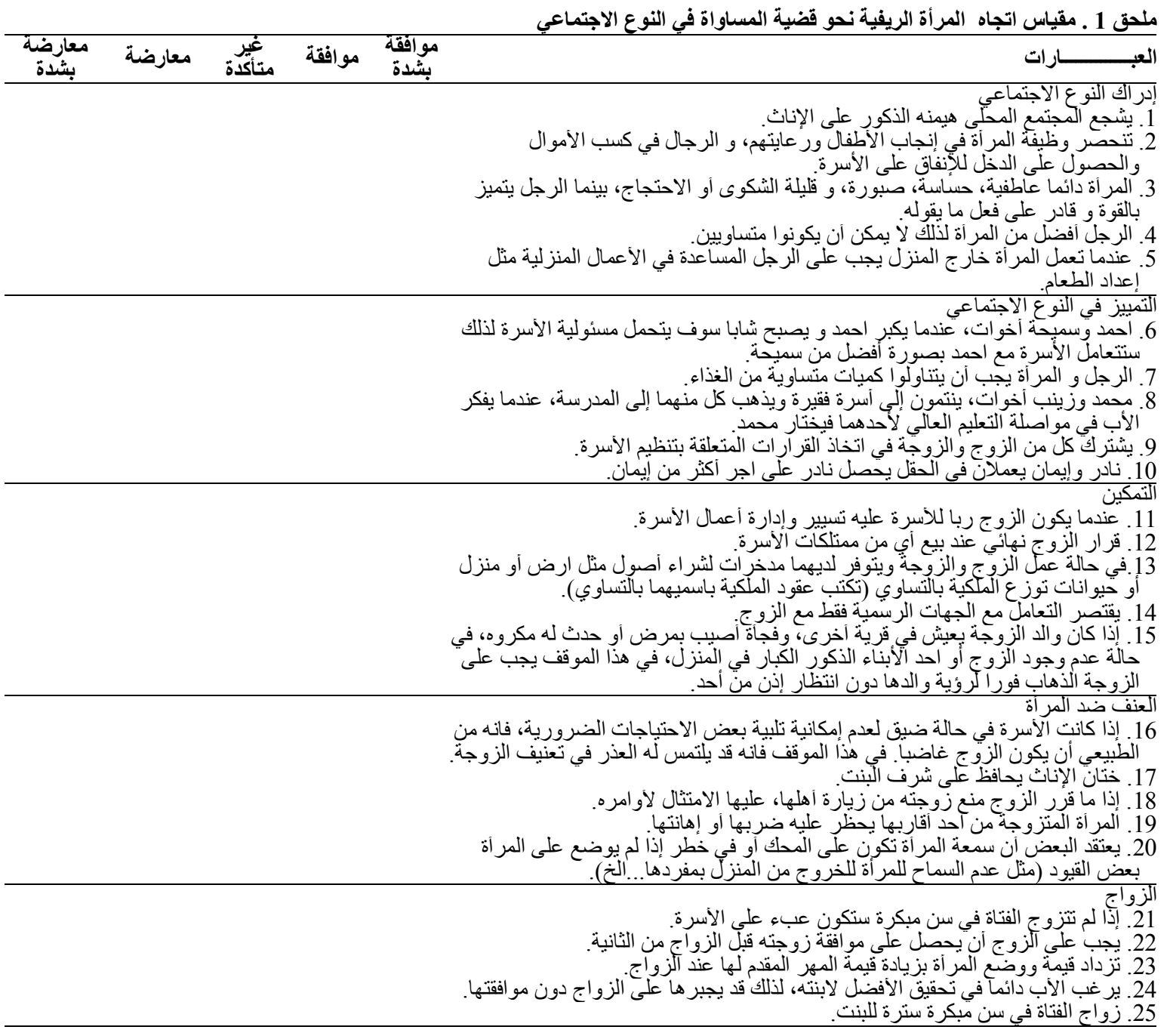




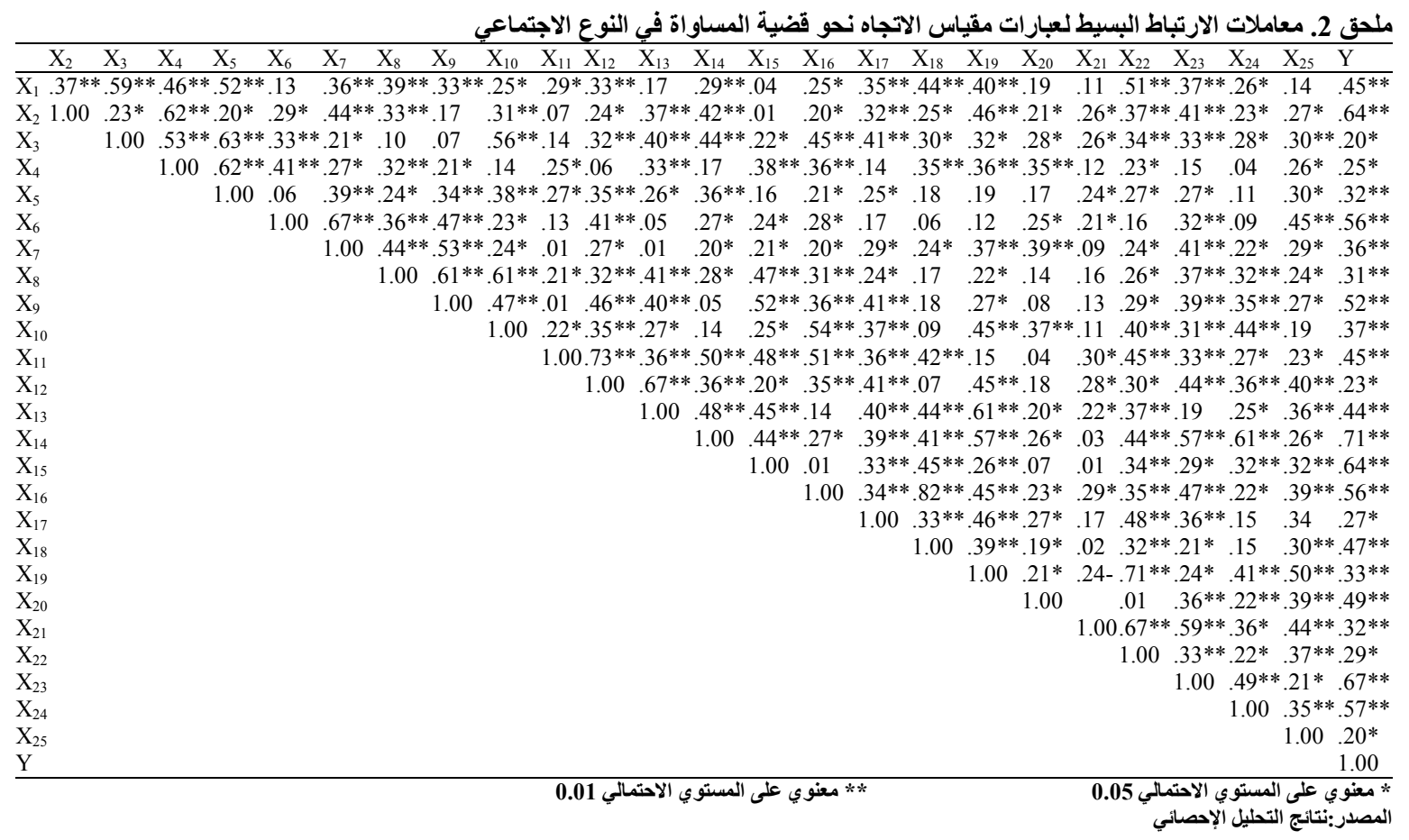

\title{
The Impact of Learning Methods Used in Literacy on the Attitudes of Rural Women Towards Gender Equality Issue. (A Comparative Study Between "Reflect Method" (Learning for Life) and The "Traditional Method" (Etalem Etnawar) in Manshaat Alkeram Village, Shebin Alqanater District, Kalyoubia Governorate, Egypt. Jacinthe I. Rihan \\ Rural Sociology and Agriculture Extension Department, Faculty of Agriculture, Ain shams University, Arab Republic of Egypt.
}

\begin{abstract}
Illiteracy in Egypt among rural women is one of the problems hindering the development and reform efforts. The percentage of illiterate females in rural areas is $38.8 \%$ of the total females 10 years and above, compared with $25.9 \%$ of the total males 10 years and above in rural areas according to the 2017 population census. Despite the massive efforts made by the government in combating illiteracy, the problem remains, and presents a serious challenge to Egypt's social and economic development. The General Authority for literacy and Adult Education, as the official body responsible for the eradication of illiteracy, has for a long time adopted a traditional program (Etalem Etnawar) of learning based primarily on alphabetical literacy and numeracy, without giving adequate attention to issues of life, personal and social empowerment for participants, including gender equality issues. Recently, The General Authority for literacy and Adult Education has begun to adopt some other learning programs and methodologies, such as the REFLECT methodology for participatory learning. The present research aims to compare the impact of the learning methods used in literacy (REFLECT method and the traditional method) on the attitudes of rural women towards the issue of gender equality. In order to achieve the research objective, two equal random samples were withdrawn of girls/women from age 15-35 years and graduates from literacy classes during the period of 2012 to 2014 from Manshaat Alkeram village, Shebin Al-Qanater district, Kalyoubia governorate, Egypt. The first sample included 35 girls/women studied and graduated from literacy classes using the traditional method (Etalem Etnawar), while the second sample included 35 girls/women studied and graduated from literacy classes using REFLECT method (Learning for Life).Using the five-dimensions Likert method and both MannWhiteny test and t-test for the difference between two independent samples, the research found statistical significant differences between the respondents' of the two samples concerning their attitude towards gender equality issue in favor of REFLECT methodology at the level of significance 0.01 .
\end{abstract}

Keywords: Literacy, Participatory learning, REFLECT method. 